\title{
Catastrophic NAD+ Depletion in Activated T Lymphocytes Through Nampt Inhibition Reduces Demyelination and Disability in EAE
}

\section{Citation}

Bruzzone, Santina, Floriana Fruscione, Sara Morando, Tiziana Ferrando, Alessandro Poggi, Anna Garuti, Agustina D'Urso, et al. 2009. Catastrophic NAD Depletion in Activated T Lymphocytes through Nampt Inhibition Reduces Demyelination and Disability in EAE. PLoS ONE 4(11): e7897.

\section{Published Version}

doi://10.1371/journal.pone.0007897

\section{Permanent link}

http://nrs.harvard.edu/urn-3:HUL.InstRepos:5765205

\section{Terms of Use}

This article was downloaded from Harvard University's DASH repository, and is made available under the terms and conditions applicable to Other Posted Material, as set forth at http:// nrs.harvard.edu/urn-3:HUL.InstRepos:dash.current.terms-of-use\#LAA

\section{Share Your Story}

The Harvard community has made this article openly available.

Please share how this access benefits you. Submit a story.

\section{Accessibility}




\title{
Catastrophic NAD ${ }^{+}$Depletion in Activated T Lymphocytes through Nampt Inhibition Reduces Demyelination and Disability in EAE
}

\author{
Santina Bruzzone ${ }^{19}$, Floriana Fruscione ${ }^{29}$, Sara Morando ${ }^{39}$, Tiziana Ferrando ${ }^{3}$, Alessandro Poggi ${ }^{4}$, Anna \\ Garuti ${ }^{5}$, Agustina D'Urso ${ }^{6}$, Martina Selmo ${ }^{3}$, Federica Benvenuto ${ }^{3}$, Michele Cea ${ }^{5}$, Gabriele Zoppoli ${ }^{5}$, Eva \\ Moran $^{5}$, Debora Soncini ${ }^{5}$, Alberto Ballestrero ${ }^{5}$, Bernard Sordat ${ }^{7}$, Franco Patrone ${ }^{5}$, Raul Mostoslavsky ${ }^{6}$, \\ Antonio Uccelli ${ }^{3}$, Alessio Nencioni ${ }^{5 *}$
}

1 Department of Experimental Medicine, Section of Biochemistry, University of Genoa, Genoa, Italy, 2 Advanced Biotechnology Center, Genoa, Italy, 3 Department of Neurosciences, Ophthalmology and Genetics, University of Genoa, Genoa, Italy, 4 Laboratory of Immunology, Department of Translational Oncology, National Institute for Cancer Research, Genoa, Italy, 5 Department of Internal Medicine, University of Genoa, Genoa, Italy, $\mathbf{6}$ Department of Medicine, Massachusetts General Hospital Cancer Center, Harvard Medical School, Boston, Massachusetts, United States of America, $\mathbf{7}$ Laboratory of Glycochemistry and Asymmetric Synthesis, Swiss Federal Institute of Technology (EPFL), Batochime, Lausanne, Switzerland

\begin{abstract}
Nicotinamide phosphoribosyltransferase (Nampt) inhibitors such as FK866 are potent inhibitors of NAD ${ }^{+}$synthesis that show promise for the treatment of different forms of cancer. Based on Nampt upregulation in activated T lymphocytes and on preliminary reports of lymphopenia in FK866 treated patients, we have investigated FK866 for its capacity to interfere with T lymphocyte function and survival. Intracellular pyridine nucleotides, ATP, mitochondrial function, viability, proliferation, activation markers and cytokine secretion were assessed in resting and in activated human T lymphocytes. In addition, we used experimental autoimmune encephalomyelitis (EAE) as a model of T-cell mediated autoimmune disease to assess FK866 efficacy in vivo. We show that activated, but not resting, T lymphocytes undergo massive NAD depletion upon FK866mediated Nampt inhibition. As a consequence, impaired proliferation, reduced IFN- $\gamma$ and TNF- $\alpha$ production, and finally autophagic cell demise result. We demonstrate that upregulation of the NAD ${ }^{+}$-degrading enzyme poly-(ADP-ribose)polymerase (PARP) by activated T cells enhances their susceptibility to NAD ${ }^{+}$depletion. In addition, we relate defective IFN- $\gamma$ and TNF- $\alpha$ production in response to FK866 to impaired Sirt6 activity. Finally, we show that FK866 strikingly reduces the neurological damage and the clinical manifestations of EAE. In conclusion, Nampt inhibitors (and possibly Sirt6 inhibitors) could be used to modulate $T$ cell-mediated immune responses and thereby be beneficial in immune-mediated disorders.
\end{abstract}

Citation: Bruzzone S, Fruscione F, Morando S, Ferrando T, Poggi A, et al. (2009) Catastrophic NAD ${ }^{+}$Depletion in Activated T Lymphocytes through Nampt Inhibition Reduces Demyelination and Disability in EAE. PLoS ONE 4(11): e7897. doi:10.1371/journal.pone.0007897

Editor: Colin Combs, University of North Dakota, United States of America

Received June 20, 2009; Accepted October 22, 2009; Published November 19, 2009

Copyright: ( 2009 Bruzzone et al. This is an open-access article distributed under the terms of the Creative Commons Attribution License, which permits unrestricted use, distribution, and reproduction in any medium, provided the original author and source are credited.

Funding: This study was supported by the Associazione Italiana per la Ricerca sul Cancro (AIRC, A.N.), the Associazione Italiana contro le Leucemie, Linfomi e Mieloma (AlL; A.B. and F.P.), and by the University of Genoa. R.M. is a V Scholar, a Sidney Kimmel Foundation Scholar, and is supported by a grant from the American Federation of Aging Research. The funders had no role in study design, data collection and analysis, decision to publish, or preparation of the manuscript.

Competing Interests: The authors have declared that no competing interests exist.

*E-mail: A.Nencioni@gmx.net

These authors contributed equally to this work

\section{Introduction}

FK866 (formerly WK175) is a potent inhibitor of nicotinamide phosphoribosyltrabsferase (Nampt), the key enzyme in the $\mathrm{NAD}^{+}$ synthesis pathway from Nam $[1,2,3]$. Initial studies carried out in cancer cell lines indicated that exposure to FK866 results in a slowly progressing form of cell death due to intracellular $\mathrm{NAD}^{+}$depletion $[1,4]$. Following preclinical evaluation in animal models, FK866 underwent clinical experimentations in patients with advanced solid tumors showing some activity and acceptable toxicity [5]. Subsequent studies demonstrated that the activity of FK866 is improved when the drug is used in combination with ionizing radiations and with DNA damaging agents as these treatments result in activation of the $\mathrm{NAD}^{+}$-degrading enzyme poly-(ADP-ribose) polymerase (PARP) which in turn cooperates to lower $\mathrm{NAD}^{+}$levels in the cell $[6,7,8]$.
The preclinical studies and the clinical experimentation revealed that lymphocytes are probably the normal cell type that is most sensitive to FK866 since lymphopenia was consistently observed in response to this drug [5]. In line with these findings, using a mouse strain lacking Nampt expression in the T and B cell lineage, Rongavaux and colleagues have recently shown that Nampt is critically required for the development of both $\mathrm{T}$ and $\mathrm{B}$ lymphocytes [9]. Finally, T lymphocytes upregulate Nampt in response to mitogenic stimuli $[10,11,12,13]$, suggesting that Nampt activity may be especially required during the process of T lymphocyte activation.

Here, we evaluated FK866 for its capacity to interfere with T lymphocyte function and survival and assessed the mechanisms underlying FK866 efficacy in these cells. We show that Nampt inhibition with FK866 has catastrophic consequences in activated 
$\mathrm{T}$ cells where it virtually obliterates intracellular $\mathrm{NAD}^{+}$stores leading to functional impairment and ultimately to autophagic cell demise. In line with these premises, we show that FK866 strikingly ameliorates the manifestations of experimental autoimmune encephalomyelitis (EAE), a prototypical model of T-cell mediated autoimmune disorder. Our data provide the rational for the evaluation of Nampt inhibitors in immune mediated disorders.

\section{Results}

FK866 Prevents T Lymphocyte Proliferation and Selectively Affects Viability of Activated T Lymphocytes

The capacity of FK866 to interfere with $\mathrm{T}$ lymphocyte responses was initially tested in proliferation assays which showed how this compound virtually abrogates $\mathrm{T}$ cell proliferation in response to mitogenic stimulation (Figure 1A and data not shown). Proliferation inhibition was typically accompanied by morphological changes suggestive of cell demise (data not shown). Therefore we assessed whether FK866 would affect T cell viability and whether resting and activated $\mathrm{T}$ lymphocytes would behave differently in terms of susceptibility to this drug. We found that FK866 was toxic to PBLs when these were concomitantly activated with mitogens [phytohematoagglutininP (PHA), or concanavalin A (Con A)], while unstimulated cells were mostly unaffected (Figure 1B). Similarly, activation with allogeneic DCs also sensitized PBLs to FK866-induced cell demise while unstimulated PBLs were less affected (Figure 1C, D). As detected after a five-day treatment, FK866-induced cell death in activated PBLs was concentration dependent, with EC50s comprised between 1 and $10 \mathrm{nM}$, and typically reached a plateau starting from $30 \mathrm{nM}$ (Figure 1B, C). In resting PBLs, FK866 EC50 was never reached in the concentration range we used. In experiments where FK866 treatment $(33 \mathrm{nM})$ was extended for up to 12 days, unstimulated PBLs were still $>80 \%$ viable indicating that resting $\mathrm{T}$ cells are mostly resistant to FK866-induced cell death (data not shown). Similarly, FK866
A

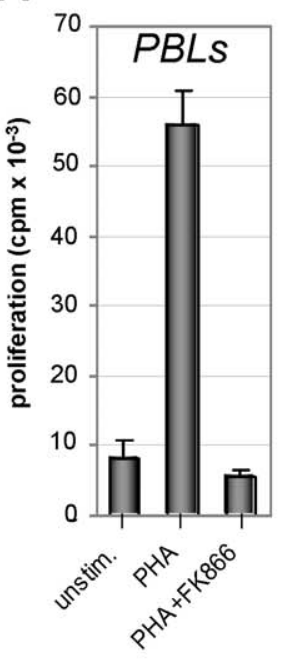

B

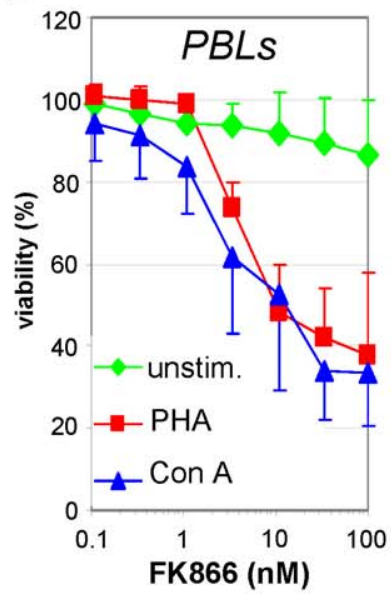

C

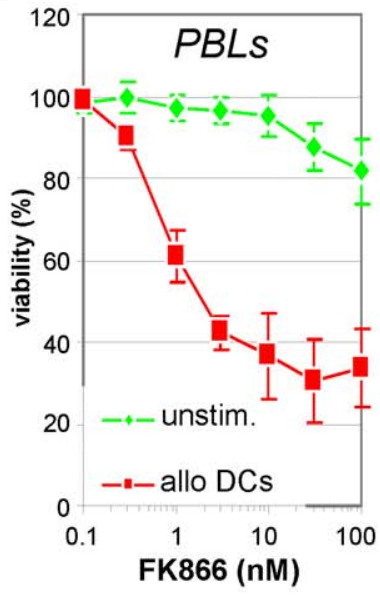

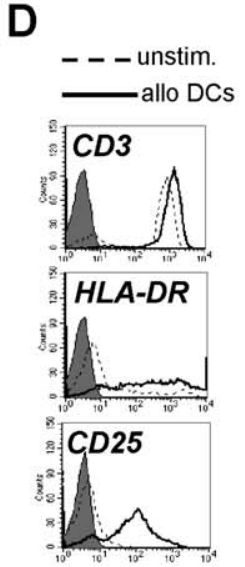

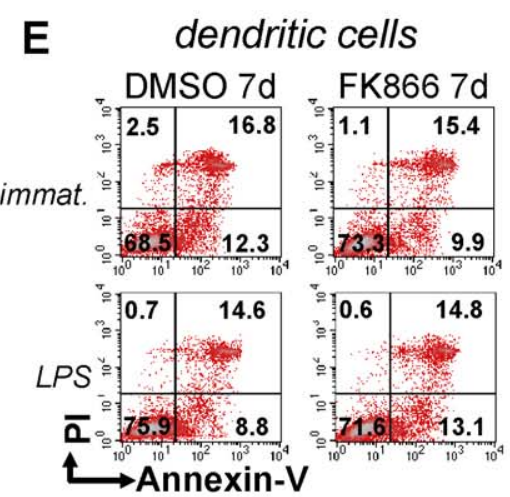

F $\quad P B L s$
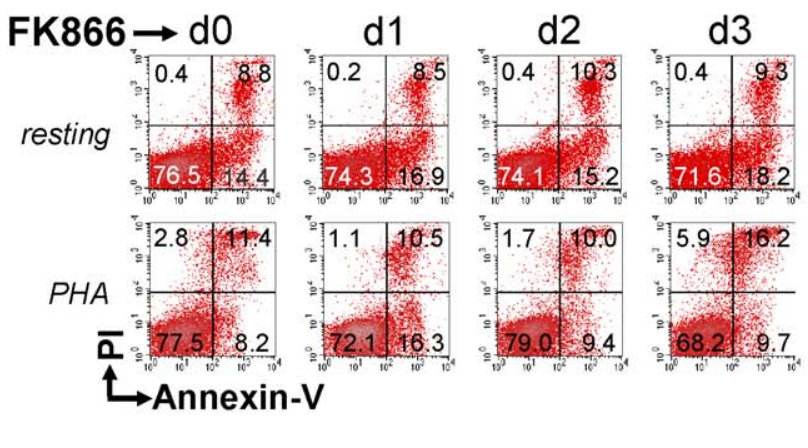

d4
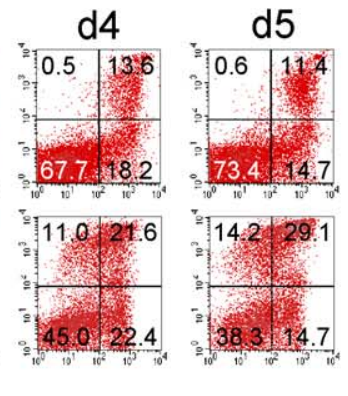

Figure 1. Nampt inhibition with FK866 prevents T lymphocyte proliferation and selectively kills activated T cells. A, PBLs were seeded in 96-well plates in the presence or absence (unstim.) of PHA and $33 \mathrm{nM}$ FK866. Proliferation was assessed $96 \mathrm{~h}$ later by standard [ ${ }^{3} \mathrm{H}$ ]thymidine incorporation assay. B, PBLs were incubated in 96-well plates in the presence or absence of $5 \mu \mathrm{g} / \mathrm{ml} \mathrm{PHA}, 1 \mu \mathrm{g} / \mathrm{ml}$ Con A, with or without the indicated concentrations of FK866. Five days later viability was detected by PI staining and flow cytometry. Spontanous cell death was $12.2 \%$ and 28.1\% for PHA- and Con A-stimulated PBLs, respectively. C, D, PBLs were stimulated for 7 days with or without allogeneic mature DCs before FK866 at the indicated concentrations was added. After 5 days viability was assessed by PI staining and flow cytometric analysis using the lymphocyte gate (C). Spontaneous PBL death was 18.4\%. D: phenotype of unstimulated or DC-stimulated PBLs. E, Immature or LPS stimulated DCs were cultured for 7 days with $33 \mathrm{nM}$ FK866 before staining with FITC-conjugated Annexin-V and PI and flow cytometry. F, Resting or PHA-stimulated PBLs were treated with $33 \mathrm{nM}$ FK866 for the indicated times and subsequently stained with FITC-conjugated Annexin-V and PI for flow cytometric analysis. Mean values \pm SD of five (B) and three $(A, C)$ different donors are presented. D-F One representative experiment out of three is shown. doi:10.1371/journal.pone.0007897.g001 
did not affect viability of dendritic cells (DCs) or NK cells even after protracted exposure (Figure $1 \mathrm{E}$ and data not shown). Activated $\mathrm{T}$ lymphocyte death in response to FK866 was typically a slowly progressing form of cell demise as an increase in the rate of dead $\mathrm{T}$ lymphocytes was normally observed starting from $72 \mathrm{~h}$ treatment (Figure $1 \mathrm{~F}$ ).

CD3-neg PB mononuclear cells (PBMCs) were less than 20\% of the PBL preparations and this percentage further decreased on exposure to $\mathrm{T}$ cell mitogens or to allogeneic DCs $(<10 \%)$ (Figure 1D and data not shown). In order to exclude that $\mathrm{T}$ lymphocyte death induced by FK866 was mediated by the contaminating PBMCs, we performed similar experiments using highly pure $\mathrm{CD}^{+}$cells isolated by magnetic cell sorting (>95\%). These tests reproduced the results shown in Figure 1B-C, confirming that FK866 primarily targets activated T lymphocytes (data not shown).

\section{Activated PBLs Undergo Massive NAD(H) Depletion following Nampt Inhibition}

We next sought to determine whether the increased toxicity of Nampt inhibition in activated as compared to resting PBLs would reflect a different response to the drug in terms of intracellular levels of pyridine nucleotides. Intracellular $\mathrm{NAD}(\mathrm{H})$ and $\operatorname{NADP}(\mathrm{H})$ were measured by cycling enzymatic assays, whereas ATP levels were determined by HPLC. In resting PBLs, the mean $\mathrm{NAD}^{+}, \mathrm{NADH}, \mathrm{NADP}^{+}$, and NADPH intracellular amounts were $88 \pm 15$ pmoles $/ 10^{6}$ cells, $12.3 \pm 0.5$ pmole $/ 10^{6}$ cells, $4.2 \pm 0.7$ pmoles $/ 10^{6}$ cells, and $21.7 \pm 0.7$ pmoles $/ 10^{6}$ cells, respectively. In mitogen-stimulated PBLs, the mean $\mathrm{NAD}^{+}, \mathrm{NADH}, \mathrm{NADP}^{+}$, and NADPH levels were $295.6 \pm 5.9$ pmoles $/ 10^{6}$ cells, $60.9 \pm 2.1$ pmoles $/ 10^{6}$ cells, $7.1 \pm 0.7$ pmoles $/ 10^{6}$ cells, and $94.6 \pm 5.6$ pmoles $/ 10^{6}$ cells, respectively. The absolute values of pyridine nucleotides concentrations and their increased content in mitogen-stimulated PBLs are in line with those detected in previous studies [14]. Treatment with FK866 significantly reduced intracellular $\mathrm{NAD}^{+}$levels in both resting and activated T lymphocytes (Figure 2A). However, while unstimulated PBLs retained on average about $20 \%$ of their intracellular $\mathrm{NAD}^{+}$ content when exposed to $33 \mathrm{nM}$ FK866 (range 11.8\%-32\%), in mitogen-stimulated T lymphocytes FK866 typically reduced intracellular $\mathrm{NAD}^{+}$to less than $5 \%$ of the levels in FK866untreated cells (range 0.6-7.4\%). In activated PBLs treated with FK866, both the absolute $\mathrm{NAD}^{+}$amount and the percentage of $\mathrm{NAD}^{+}$content relative to FK866-untreated controls were significantly lower than those detected in resting PBLs (Figure 2B). NADH levels closely paralleled $\mathrm{NAD}^{+}$levels in response to FK866 (Figure 2C). Vice versa, $\mathrm{NADP}^{+}$and particularly NADPH levels were depleted by FK866 to a much lesser extent. Thus, Nampt inhibition appears to primarily affect the $\operatorname{NAD}(\mathrm{H})$ pool in T lymphocytes. Figure 2D shows a time course experiment where intracellular $\mathrm{NAD}^{+}$and ATP level, and cell viability were monitored simultaneously in activated PBLs treated with FK866. A significant $\mathrm{NAD}^{+}$decrease was detected as early as $3 \mathrm{~h}$ after addition of FK866 (Figure 2D). This was followed by a decrease in intracellular ATP, which became apparent between 12 and $24 \mathrm{~h}$ after drug addition. Finally, a decrease in cell viability was detected $72 \mathrm{~h}$ after onset of FK866 treatment. These data indicate that $\mathrm{T}$ lymphocyte death due to Nampt inhibition is preceded by a period of several hours when cells are viable despite very low $\mathrm{NAD}^{+}$levels and decreasing ATP content. Exogenously added $\mathrm{NAD}^{+}$completely rescued FK866-induced PBL death confirming that the effect of FK866 on PBLs viability is indeed a consequence of $\mathrm{NAD}^{+}$-shortage (Figure 2E).

\section{PARP and Sirtuin Activity Predispose Activated T} Lymphocytes to Intracellular $\mathrm{NAD}^{+}$Depletion

DNA-damaging agents leading to PARP activation were previously shown to increase FK866 activity [6,7]. In activated T lymphocytes, a marked increase in PARP activity occurs to ensure efficient DNA repair and possibly to implement signal transduction $[10,15,16]$. Therefore, we assessed whether PARP is involved in conferring susceptibility to FK866 to activated T cells. We first verified by quantitative PGR (Q-PCR) (Figure 3A) and by Western blotting (not shown) that PARP1 and Nampt become upregulated in PBLs in response to mitogenic stimulation. Three structurally unrelated PARP inhibitors, NU1025, 3-AB, and PJ34 indeed provided a partial rescue of intracellular $\mathrm{NAD}^{+}$levels upon treatment of activated PBLs with FK866 (Figure 3B). This effect was paralleled by an increase in cell viability (Figure 3C). NU1025, 3-AB, and PJ34 had no effect on T lymphocyte proliferation in response to mitogens (data not shown). Thus, the protection conferred by these compounds against FK866-induced cell demise is not attributable to inhibition of T lymphocyte activation. In line with a recent report [4], we found that several $\mathrm{T}$ cell leukemia cell lines are highly susceptible to FK866 (not shown). In Jurkat cells, NU1025, 3-AB, and PJ34 alleviated FK866-induced $\mathrm{NAD}^{+}$ depletion (Fig. 3D) and virtually completely prevented cell death induced by low FK866 concentrations $(<500 \mathrm{pM})$ in a concentration dependent fashion (Figure 3E). However, similarly to what observed in primary PBLs, at higher FK866 concentrations the protection conferred by PARP inhibitors to Jurkat cells and to other T cell leukemia cell lines was only partial (not shown).

The fact that PARP inhibitors only partially block FK866induced $\mathrm{NAD}^{+}$shortage and cell death in activated $\mathrm{T}$ cells suggests that other enzymatic activities/metabolic processes could come into play to enhance susceptibility to FK866. The ADP-ribosyl cyclase CD38 is also upregulated in T cells by activation stimuli [17]. The possible contribution of CD38 to the enhanced sensitivity of activated T lymphocytes to FK866 was first assessed by transfecting Jurkat cells with CD38-specific small interfering RNAs, in the presence or absence of FK866. CD38 silencing did not induce any significant effects on $\mathrm{NAD}^{+}$levels and on viability (data not shown). Moreover, we did not observe a difference in the sensitivity to FK866 between HeLa cells transfected with sense-(CD38 ${ }^{+}$) or with anti-sense-(CD38 ${ }^{-}$) human CD38 (data not shown) [18].

Finally, sirtuins also use $\mathrm{NAD}^{+}$as a substrate [19], and some of these enzymes may undergo upregulation in activated $\mathrm{T}$ lymphocytes (see below). We found that the sirtuin inhibitor sirtinol induced a slight, although significant increase in the levels of intracellular $\mathrm{NAD}^{+}$in activated T cells exposed to FK866 (data not shown). Consistently, sirtinol mitigated FK866-induced cell death in activated PBLs (Figure 3F). Thus, sirtuin activity appears to also be among the factors involved in conferring susceptibility to FK866 to activated T cells.

\section{$\mathrm{NAD}^{+}$Depletion Induces T Lymphocyte Death via Mitochondria Dysfunction and Autophagy}

Mitochondrial oxidative phosphorylation is the cellular major ATP source under aerobic conditions. NADH is required for mitochondrial transmembrane potential $\left(\Delta \Psi_{\mathrm{m}}\right)$ maintenance which in turn is a prerequisite for ATP generation [20]. We found that in primary activated PBLs as well as in T cell leukemia cell lines $\Delta \Psi_{\mathrm{m}}$ is dissipated following $\mathrm{FK} 866$-induced $\mathrm{NAD}^{+}$ depletion (Figure $4 \mathrm{~A}$ and data not shown). $\Delta \Psi_{\mathrm{m}}$ loss due to Nampt inhibition was more pronounced in activated than in resting PBLs (Figure $4 \mathrm{~B}$ ). To demonstrate that $\Delta \Psi_{\mathrm{m}}$ loss is causally involved in FK866-mediated cell death we made use of Jurkat cells engineered to overexpress $\mathrm{Bcl} 2$ as this antiapoptotic protein maintains $\Delta \Psi_{\mathrm{m}}$ in 
A

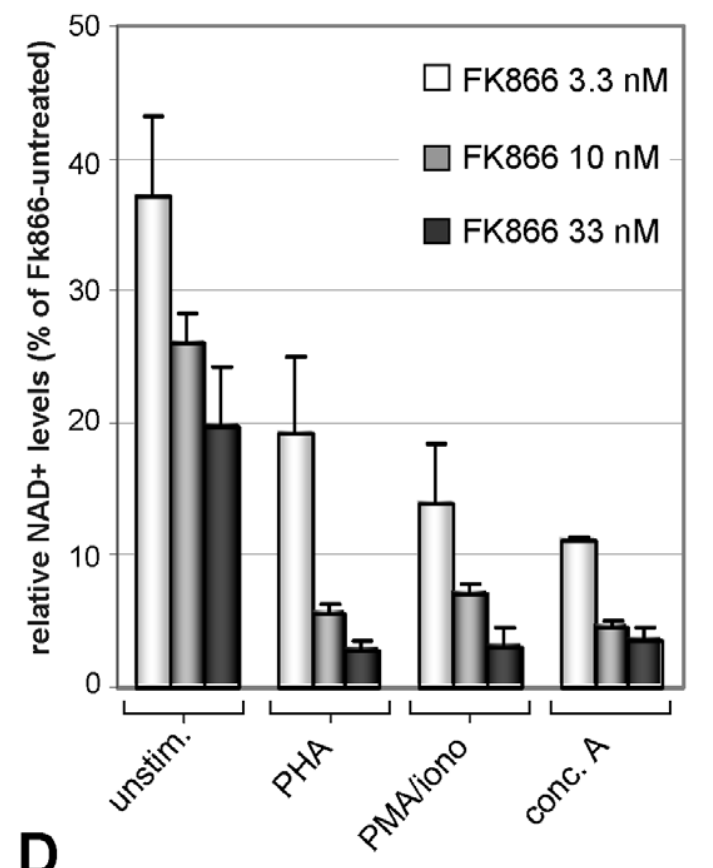

B

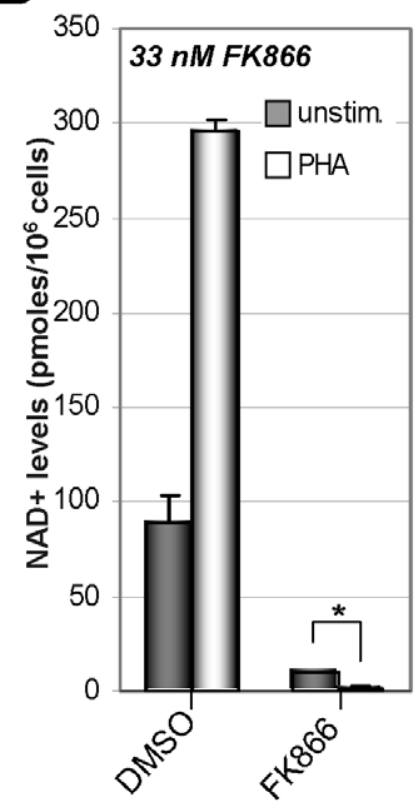

C

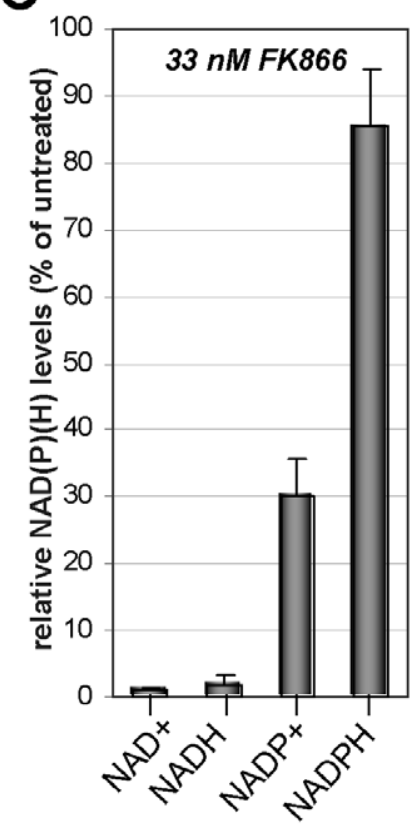

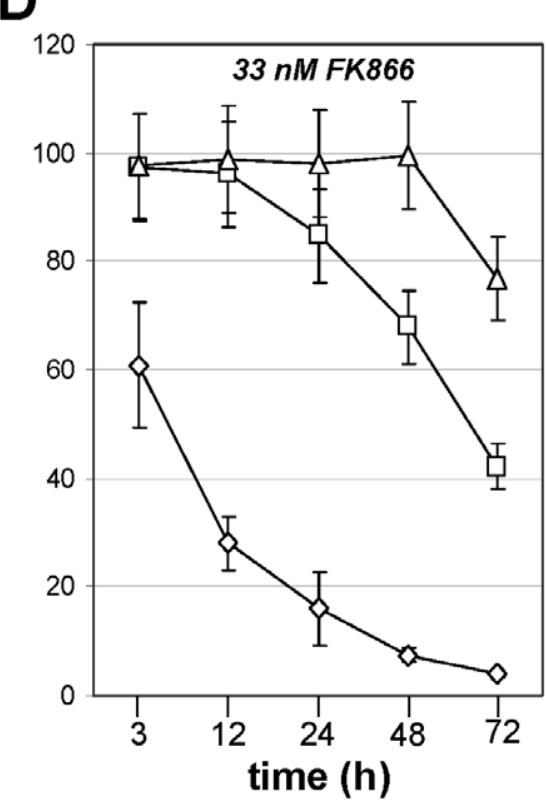

$\checkmark$ relative NAD+ levels (\% of untreated)

$-\square$ relative ATP levels (\% of untreated) $\triangle$ viability

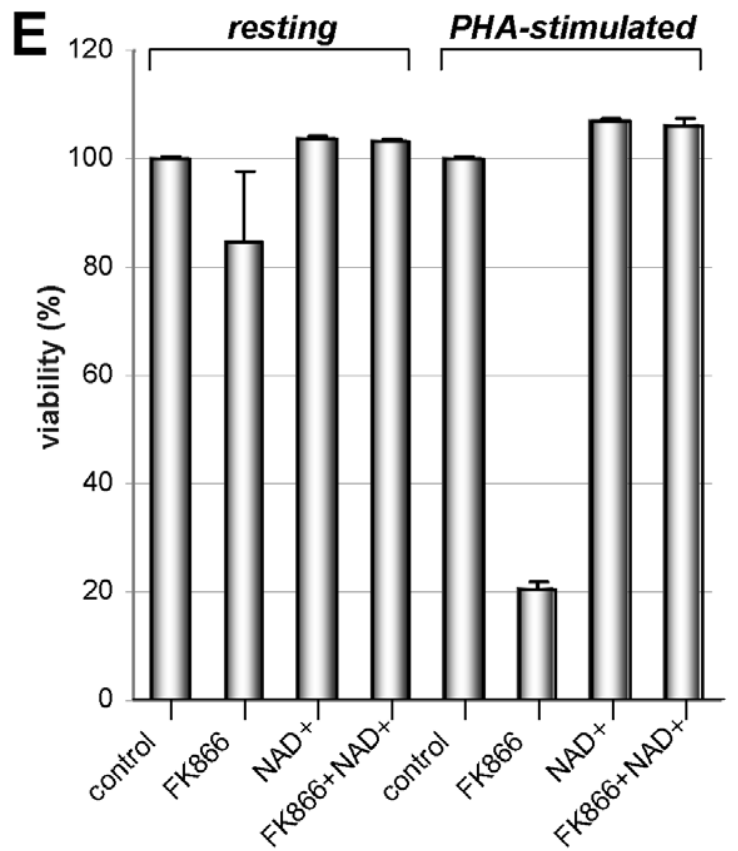

Figure 2. Activated T cells undergo massive NAD ${ }^{+}$depletion upon Nampt inhibition. $A, 3 \times 10^{6} \mathrm{PBLs} /$ well were stimulated (or not, unstim.) with $5 \mu \mathrm{g} / \mathrm{ml} \mathrm{PHA}, 1 \mu \mathrm{g} / \mathrm{ml}$ con A, or $50 \mathrm{ng} / \mathrm{ml} \mathrm{PMA}$ and $0.5 \mu \mathrm{M}$ ionomycin in the presence or absence of the indicated FK866 concentrations. $48 \mathrm{~h}$ later, cells were lysed in $0.6 \mathrm{M} \mathrm{PCA}$ and NAD content was measured in neutralized extracts. NAD levels were normalized to those detected in the absence of FK866. B, Unstimulated or PHA-stimulated PBLs were treated with $33 \mathrm{nM}$ FK866 for $48 \mathrm{~h}$ before NAD ${ }^{+}$content was determined. Absolute $\mathrm{NAD}^{+}$levels are presented. *: $\mathrm{p}<0.05$. C, PBLs were cultured for $48 \mathrm{~h}$ with PHA with or without FK866 (33 nM) addition. Subsequently, pyridine dinucleotides levels were measured in acid $\left(\mathrm{NAD}^{+}\right.$and $\mathrm{NAPD}{ }^{+}$) or alkaline (NADH and NADPH) cell extracts. Dinucleotide levels were normalized to those detected without FK866. D, PBLs were incubated with PHA and 33 nM FK866 for the indicated times. Thereafter cells were harvested and NAD ${ }^{+}$ and ATP levels were determined in cell extracts whereas cell viability was assessed by Pl-staining and flow cytometry. Results were normalized to the values of FK866-untreated cells. E, Resting or PHA-stimulated PBLs were treated (or not) with 33 nM FK866 in the presence or absence of 1 mM NAD'. After five-days viability was assessed determining $\mathrm{PI}^{-}$cells by flow cytometry. Results are means \pm SD of five (A) or three (B-E) experiments. doi:10.1371/journal.pone.0007897.g002

the presence of $\Delta \Psi_{\mathrm{m}}$ loss-inducing stimuli by enhancing $\mathrm{H}^{+}$efflux (Figure 4C) [21,22]. Indeed, Bcl2-overexpression protected Jurkat cells from FK866-mediated mitochondrial depolarization (Figure 4C). This effect was not due to interference by $\mathrm{Bcl} 2$ on intracellular $\mathrm{NAD}^{+}$depletion as FK866 efficiently depleted intracellular $\mathrm{NAD}^{+}$also in Bcl2-overexpressing Jurkat (data not shown). Consistent with the fact that $\Delta \Psi_{\mathrm{m}}$ is maintained by $\mathrm{Bcl} 2$ overexpression irrespective of $\mathrm{NAD}^{+}$shortage, Bcl2 Jurkat cells did 

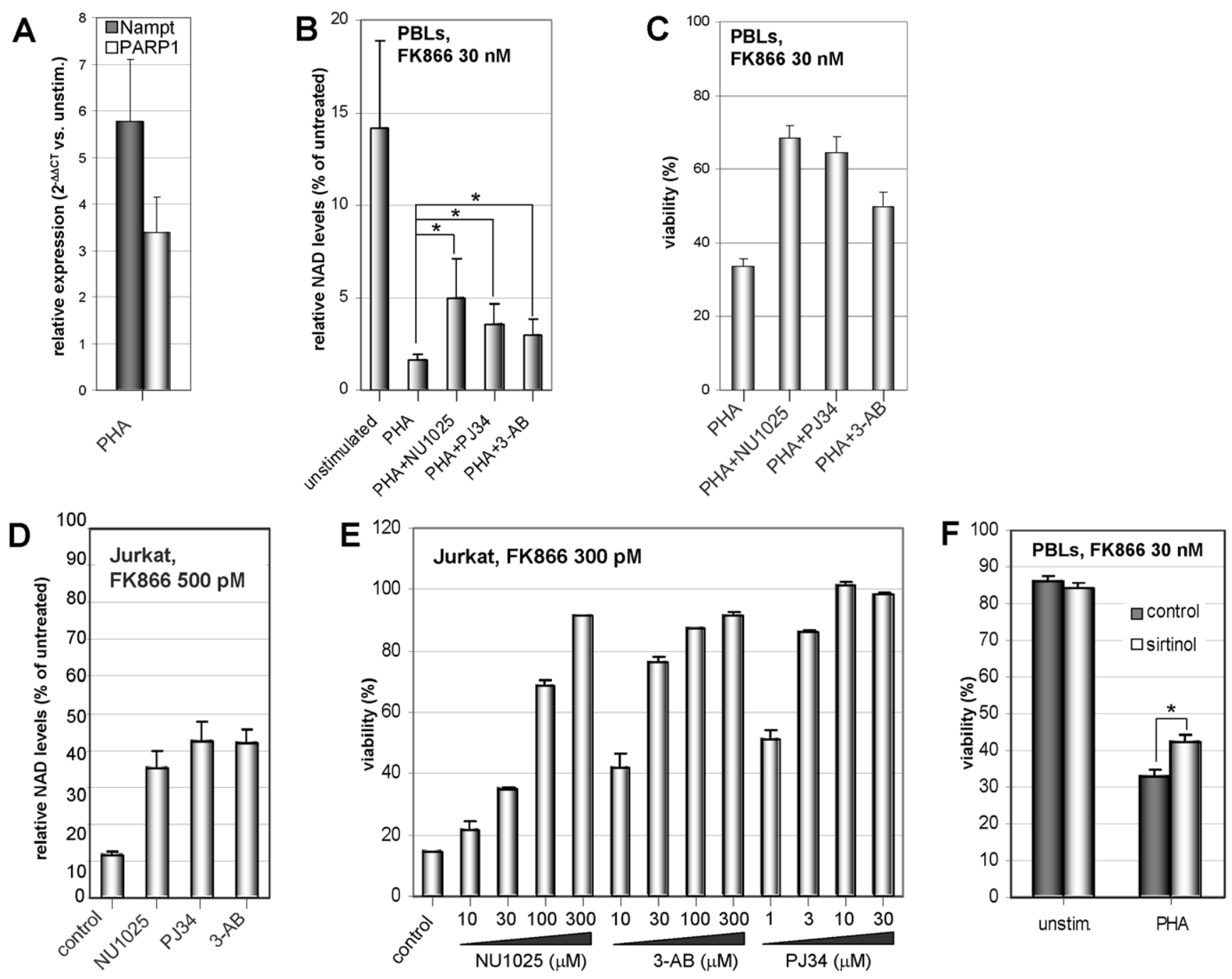

Figure 3. PARP inhibitors and sirtinol attenuate FK866-induced $\mathrm{T}$ cell demise. A, PBLs were cultured for $24 \mathrm{~h}$ with or without PHA. Thereafter, Nampt and PARP1 levels were detected by Q-PCR. mRNA levels in PHA-stimulated cells were compared to those in unstimulated PBLs. B,

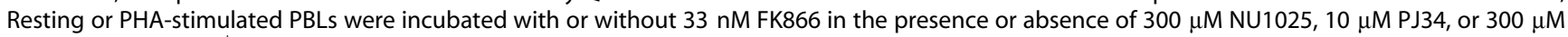
3-AB. $48 \mathrm{~h}$ later NAD ${ }^{+}$levels were assessed (presented as \% of values in FK866-untreated PBLs). ${ }^{*}, \mathrm{p}<0.05$. C, PHA-stimulated PBLs were incubated for five days with or without $33 \mathrm{nM}$ FK866 in the presence or absence of $300 \mu \mathrm{M}$ NU1025, $10 \mu \mathrm{M}$ PJ34, or $300 \mu \mathrm{M} 3-\mathrm{AB}$. Thereafter, viability was assessed. D, $5 \times 10^{5}$ Jurkat cells were treated for two days with 500 pM FK866 in the presence or absence of $300 \mu M$ NU1025, $5 \mu M$ PJ34, or 300 $\mu$ M 3-AB. Subsequently, $\mathrm{NAD}^{+}$content was determined and expressed as \% of values in FK866-untreated Jurkat. E, $3 \times 10^{4}$ Jurkat cells/well were incubated in 96-well plates with or without 300 pM FK866 in the presence or absence of the indicated concentrations of NU1025, PJ34, or 3-AB. Viability was determined $96 \mathrm{~h}$ later by PI cell staining and flow cytometry. F, PBLs were incubated for five days with PHA, with or without $33 \mathrm{nM}$ FK866, in the presence or absence of $30 \mu \mathrm{M}$ sirtinol. Viability was subsequently assessed by PI staining and flow cytometry. C, E, F, each treatment was tested in triplicate wells. Results are presented as means \pm SD of three experiments. doi:10.1371/journal.pone.0007897.g003

not show ATP depletion upon treatment with FK866 (Figure 4D). Thus, ATP reduction in response to $\mathrm{NAD}^{+}$depletion is due to $\Delta \Psi_{\mathrm{m}}$ loss. Finally, Bcl2-overexpressing Jurkat cells were virtually completely resistant to FK866-induced cell death (Figure 4E).

ATP depletion triggers autophagy [23]. To determine the role of autophagy in cell death caused by FK866 we made use of 3-MA and LY294002 two class III phosphoinisitide-3 phosphate kinase (PI3K) inhibitors known to block autophagy [24]. Both inhibitors reduced FK866-induced cell demise in PBLs (Figure 4F, G) as well as in Jurkat cells and in the T cell leukemia cell line H9 (data not shown). No protection from FK866 was conferred by the mitogenactivated protein kinase inhibitor PD098059 or by the NF- $\mathrm{BB}$ inhibitor BAY 11-7082 (data not shown). PI3K inhibition in activated PBLs had no effect on PARP upregulation in response to
PHA (not shown), ruling out that the PI3K inhibitors may interfere with FK866-induced cell death by affecting PARP. Therefore, in line with previous studies $[4,25]$, FK866 induces autophagic cell death in activated $\mathrm{T}$ lymphocytes.

Since mitochondria dysfunction is also a trigger of the intrinsic apoptotic pathway [26], we assessed whether this mechanism would also contribute to FK866 cytotoxicity. Indeed, we detected released cytochrome $c$ in the cytosolic fraction of FK866 treated T lymphocytes (not shown). However, the pan-caspase inhibitor zVAD-fmk, the caspase-9 inhibitor Z-LE(OMe)HD(OMe)-FMK, as well as the caspase-8 inhibitor $\mathrm{Z}-\mathrm{IE}(\mathrm{OMe}) \mathrm{TD}(\mathrm{OMe})-\mathrm{FMK}$ failed to protect from FK866-induced cell death (data not shown). Thus, although associated with cytochrome $c$ cytosolic relocalization, cell demise via $\mathrm{NAD}^{+}$depletion appears to occur in a caspase-independent fashion. 
A

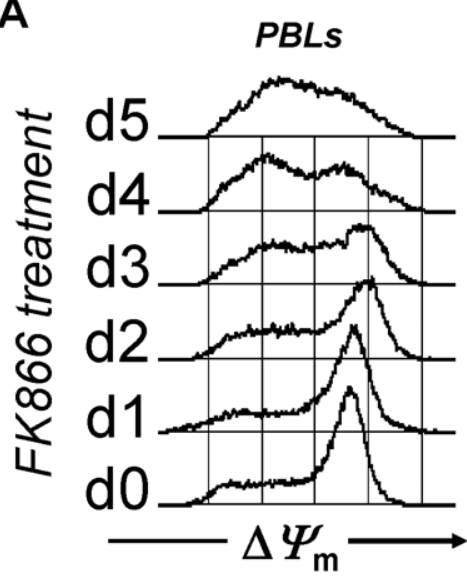

B

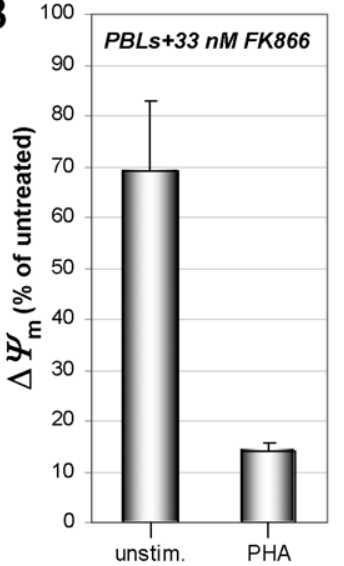

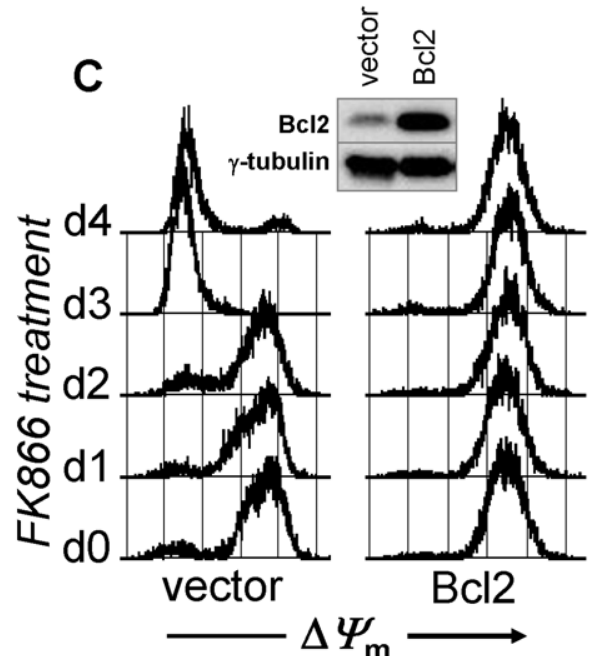

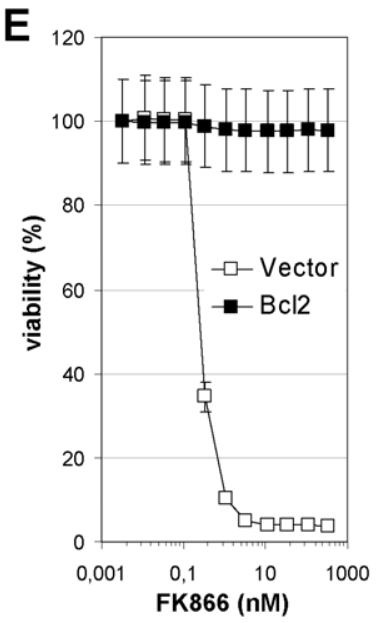

$\mathbf{F}$

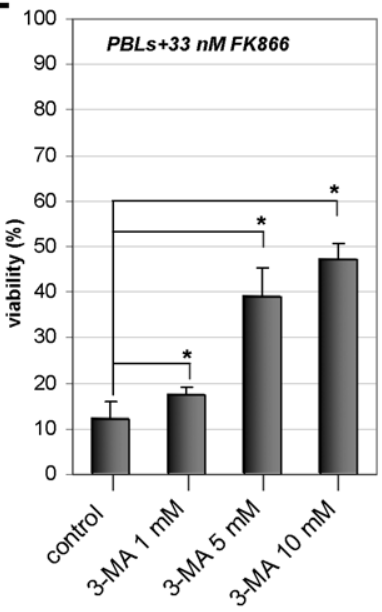

$\mathbf{G}_{12}$

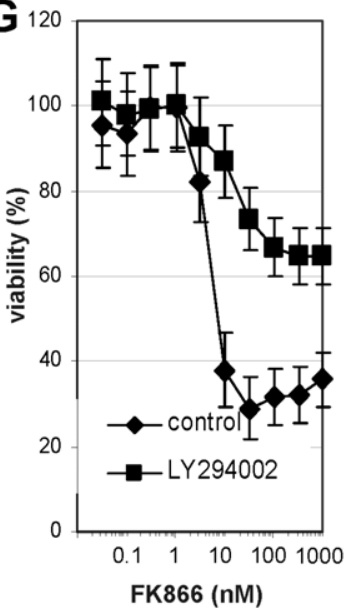

Figure 4. Nampt inhibition with FK866 induces mitochondria depolarization and ATP depletion in activated T lymphocytes. A, PHAstimulated PBLs were incubated with $33 \mathrm{nM}$ FK866 and $\Delta \Psi_{\mathrm{m}}$ was determined at the indicated days of exposure. B, Resting of PHA-stimulated PBLs were cultured with $33 \mathrm{nM}$ FK866 for five days. Thereafter PBLs with conserved $\Delta \Psi_{\mathrm{m}}$-high were quantified by flow-cytometry. C, Bcl2-overexpressing Jurkat and the respective vector control cells were incubated with $10 \mathrm{nM}$ FK866 for the indicated number of days. Thereafter, $\Delta \Psi_{\mathrm{m}}$ was determined. Inset, Western blot for $\mathrm{Bcl} 2$ and $\gamma$-tubulin expression. D, $5 \times 10^{5} \mathrm{Bcl} 2$-overexpressing Jurkat and the vector control cells were incubated with or without $10 \mathrm{nM}$ FK866 for the indicated times before ATP was detected. ATP levels are presented as \% of ATP in FK866-untreated cells. E, $3 \times 10^{4}$ Bcl2overexpressing and control Jurkat cells/well were incubated in 96-well plates with or without the indicated FK866 concentrations. Viability was determined by PI staining and flow cytometry $96 \mathrm{~h}$ later. F, PHA-stimulated PBLs were incubated in the presence or absence of $33 \mathrm{nM}$ FK866 with or without the indicated concentrations of 3-MA. Viability was detected after five days. ${ }^{*}, p<0.05$. G, PBLs incubated in $96-$ well plates in the presence of $5 \mu \mathrm{g} / \mathrm{ml} \mathrm{PHA}$ were treated for five days with the indicated FK866 concentrations in the presence or absence of $20 \mu \mathrm{M}$ LY294002. Viability was subsequently determined by PI staining and flow cytometry. B, Results are presented as means \pm SD of three experiments (B, D-G). Panels A and C are representative of three separate experiments.

doi:10.1371/journal.pone.0007897.g004

Nam and Na Prevent $\mathrm{NAD}^{+}$Shortage and Lymphocyte Death Induced by Nampt Inhibition

We performed experiments to evaluate whether FK866-induced $\mathrm{NAD}^{+}$depletion and cell death in PBLs would be prevented by Nam and by Na. Nam is known to act as an antidote for FK866 and recent studies showed that this effect may be due to direct competition for the binding site on the enzyme [1,2]. Conversely, $\mathrm{Na}$ supplementation rescues $\mathrm{NAD}^{+}$synthesis in cells that express Na phosphoribosyltransferase (Naprtl) and can thereby synthesize $\mathrm{NAD}^{+}$via the Preiss-Handler pathway $[1,27]$. Nam raised intracellular $\mathrm{NAD}^{+}$levels to over $150 \%$ of the untreated control in both FK866-treated and untreated cells (Figure 5A). We verified Naprtl expression in human PBLs by Q-PCR. Moreover, we found that Naprt 1 mRNA is upregulated in activated T cells, with the extent of the upregulation varying depending on the stimulus used (Figure 5B). Na per se did not affect intracellular $\mathrm{NAD}^{+}$levels. However, it partially prevented $\mathrm{NAD}^{+}$depletion upon treatment with FK866, to about $50 \%$ of the pyridine dinucleotide content in untreated $\mathrm{T}$ lymphocytes (Figure 5A). Both $\mathrm{Nam}$ and $\mathrm{Na}$ efficiently countered PBL death in the presence of cytotoxic FK866 concentrations (Figure 5C) and over a wide range of FK866 concentrations (Figure 5D). However, the potency of Nam and $\mathrm{Na}$ as FK866 antagonists was different: Na protected PBLs from $33 \mathrm{nM}$ FK866-induced cell death with an EC50 of $10^{-6} \mathrm{M}$ (Figure 5E, and data not shown) compared to an EC50 value for Nam of $3 \times 10^{-5}$ M. No protection from FK866-induced cell death was conferred to PBLs by tryptophan supplementation indicating that the de novo $\mathrm{NAD}^{+}$synthesis pathway is not a relevant source 
A

D
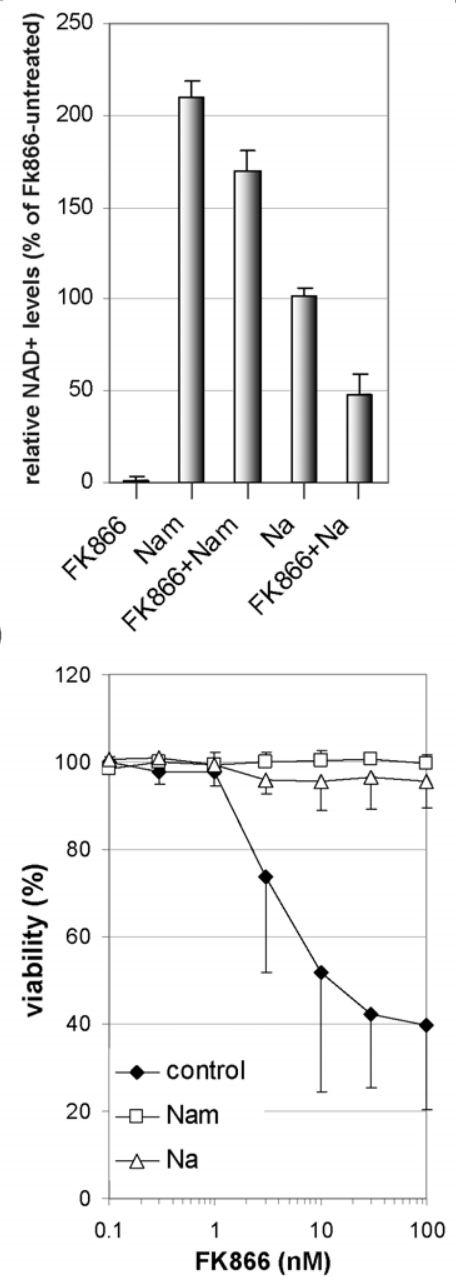

B

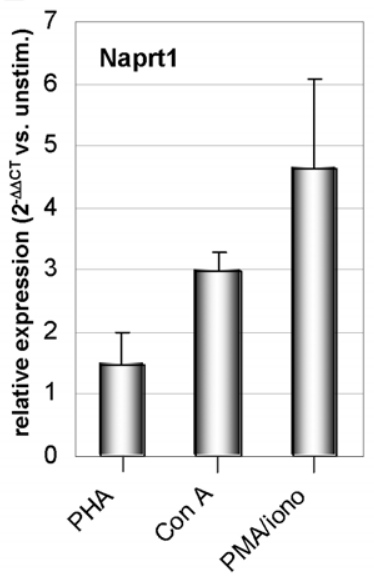

E

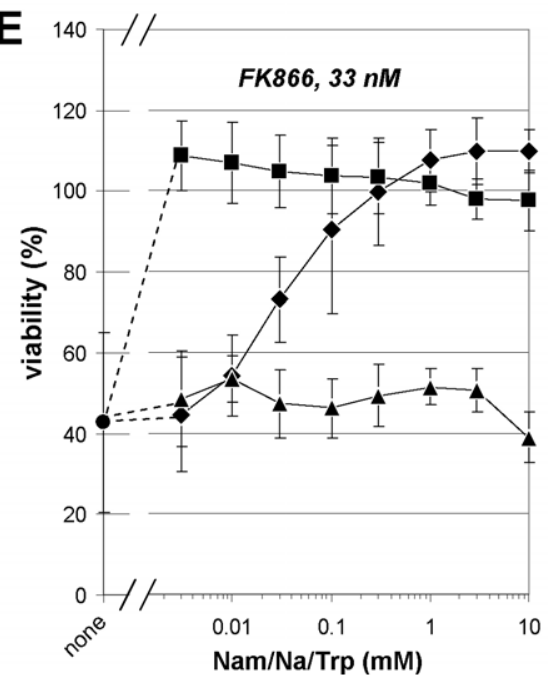

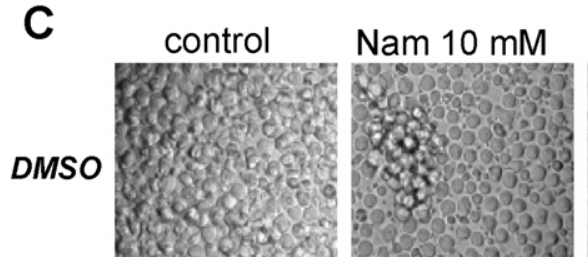

$\mathrm{Na} 10 \mu \mathrm{M}$
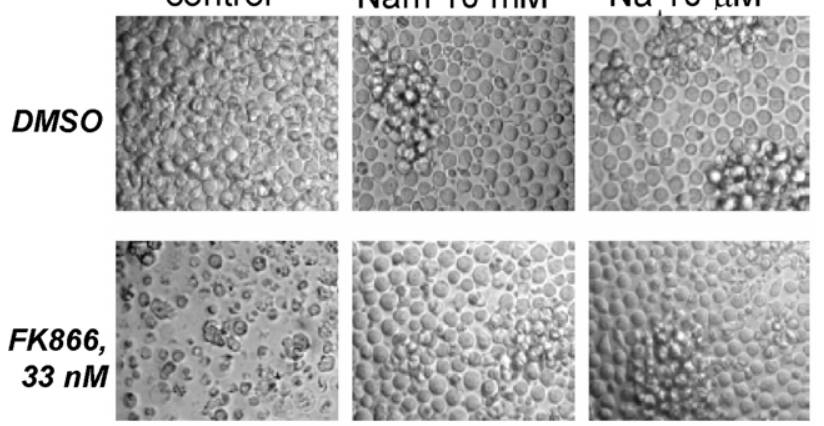

F

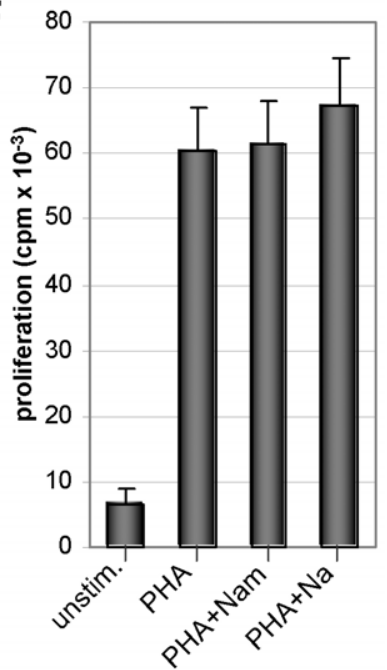

Figure 5. Nam and Na prevent NAD ${ }^{+}$shortage and cell death induced by FK866 in human T lymphocytes. A, PHA-stimulated PBLs were treated (or not) with $33 \mathrm{nM}$ FK866 in the presence or absence of $10 \mathrm{mM}$ Nam or of $10 \mu \mathrm{M}$ Na. After $48 \mathrm{~h}, \mathrm{NAD}^{+}$content was determined (expressed as percentage of NAD content in FK866-untreated cells). B, PBLs were cultured for $24 \mathrm{~h}$ with or without PHA, $1 \mu \mathrm{g} / \mathrm{ml} \mathrm{Con} \mathrm{A,} \mathrm{or} 50 \mathrm{ng} / \mathrm{ml} \mathrm{PMA}$ and $0.5 \mu \mathrm{M}$ ionomycin. Thereafter, Naprt1 mRNA levels were detected by Q-PCR. mRNA levels in mitogen-stimulated PBLs were compared to those in unstimulated PBLs. C, D, PHA-stimulated PBLs were incubated for five days with or without $10 \mathrm{mM}$ Nam or $10 \mu \mathrm{M}$ Na in the presence or absence of the indicated FK866 concentrations. Thereafter, cells were imaged by light microscopy (C), and cell viability was determined (D). E, PHA-stimulated PBLs were incubated for five days with or without $33 \mathrm{nM} \mathrm{Fk866}$ in the presence of the indicated concentrations of Nam, Na, or tryptophan (Trp). Viability was subsequently determined. F, PBLs were stimulated with or without PHA in the presence or absence of $1 \mathrm{mM}$ Nam or Na. Thymidine incorporation was measured after $48 \mathrm{~h}$ by a 16 -h pulse with $0.5 \mu \mathrm{Ci} /$ well $\left.{ }^{3} \mathrm{H}\right]$ thymidine. D-F each treatment was tested in triplicate wells. Results are means $\pm S D$ of three $(A, B, F)$ or four $(D, E)$ experiments. In panel $C$, one representative experiment out of three is shown. doi:10.1371/journal.pone.0007897.g005

of $\mathrm{NAD}^{+}$in human $\mathrm{T}$ cells [27]. Finally, Nam and Na did not exert their protective effects by interfering with the process of $\mathrm{T}$ lymphocyte activation, since proliferation (Figure $5 \mathrm{~F}$ ) and activation markers (CD25, HLA-DR, not shown) were normally induced in PBLs by PHA regardless of the presence of these metabolites.

These findings are consistent with the occurrence of the PreissHandler pathway of $\mathrm{NAD}^{+}$biosynthesis in PBLs, although its contribution to replenish the $\mathrm{NAD}^{+}$pool upon FK866 treatment seems to be limited (see Discussion).

\section{$\mathrm{NAD}^{+}$Shortage Prevents IFN- $\gamma$ Production by Activated T Lymphocytes}

Nampt inhibition and the consequent $\mathrm{NAD}^{+}$shortage were previously shown to negatively affect secretion of IL-1 $\beta$, IL-6 and TNF- $\alpha$ in macrophages and dendritic cells [28,29]. Thus, we performed experiments to determine whether $\mathrm{NAD}^{+}$depletion via FK866 would also affect cytokine secretion in T lymphocytes. These experiments were performed within $48 \mathrm{~h}$ from FK866 addition when $\mathrm{T}$ cell viability was still unaffected to be able to detect functional changes and avoid the interference of autophagic cell destruction. In this time frame, FK866 had no effect on the upregulation of activation markers such as CD25 and HLA-DR in mitogen-stimulated PBLs (Figure 6A). However, intracellular cytokine staining revealed that FK866 strongly reduced the number of TNF- $\alpha$-producing CD $3^{+} \mathrm{T}$ cells and virtually abrogated IFN- $\gamma$ synthesis (Figure 6A). These results were confirmed by direct measurement of TNF- $\alpha$ and IFN- $\gamma$ in the PBL supernatants (Figure 6B). Addition of $\mathrm{Na}$, which replenishes intracellular $\mathrm{NAD}^{+}$ stores but does not inhibit sirtuin activity (see below) [30], fully restored IFN- $\gamma$ synthesis by PBLs (Figure 6C) demonstrating that IFN- $\gamma$ downregulation was due to $\mathrm{NAD}^{+}$depletion. 
A

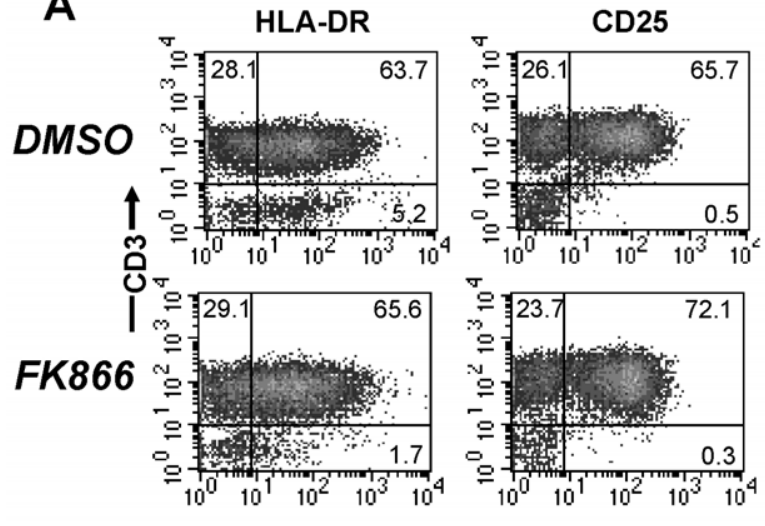

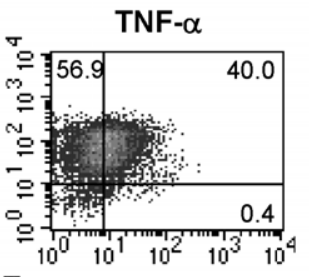
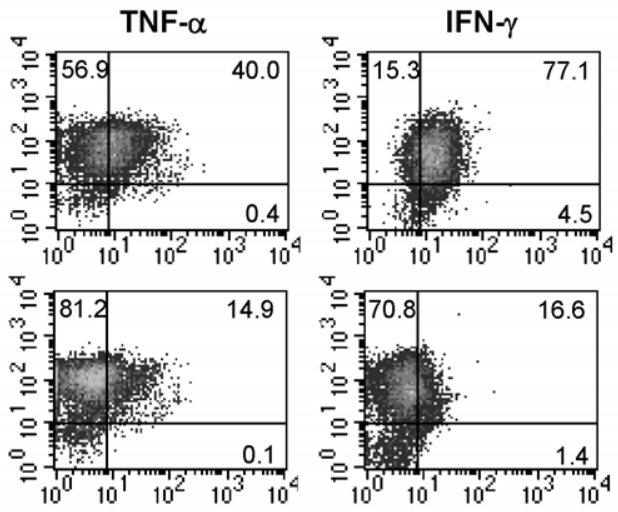

B

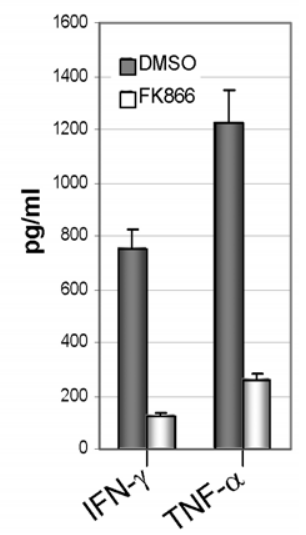

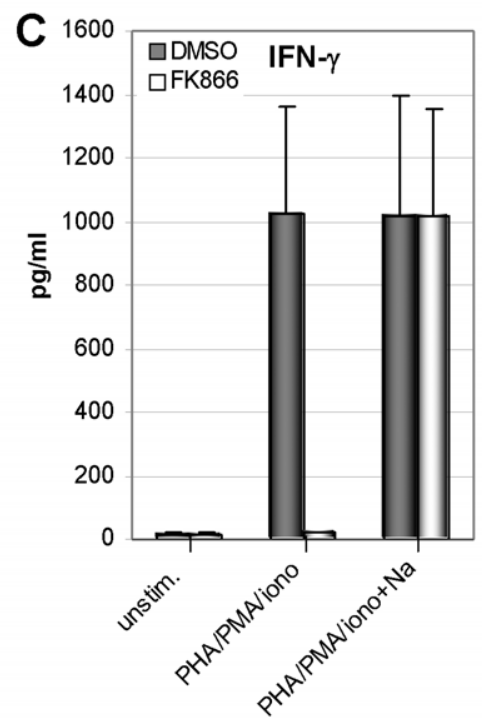
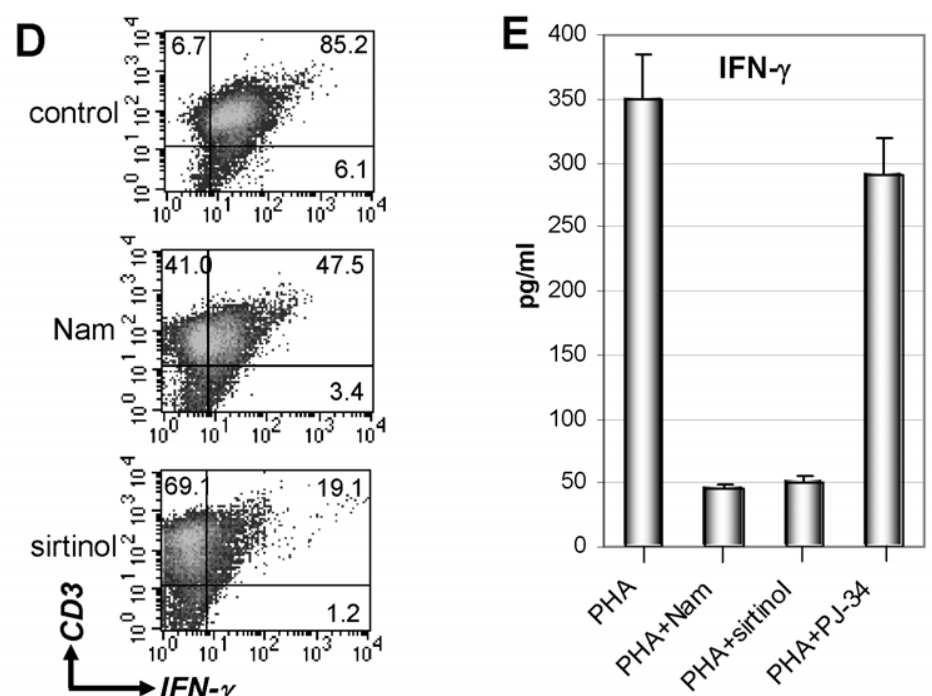

Figure 6. Intracellular NAD ${ }^{+}$depletion prevents TNF- $\alpha$ and IFN- $\gamma$ production by activated T lymphocytes. A, B, $5 \times 10^{6}$ PBLs were stimulated with $5 \mu \mathrm{g} / \mathrm{ml} \mathrm{PHA}$ with or without $33 \mathrm{nM}$ FK866 for $36 \mathrm{~h}$ and subsequently incubated with $50 \mathrm{ng} / \mathrm{ml}$ PMA and $0.5 \mu \mathrm{M}$ ionomycin for further $5 \mathrm{~h}$. Thereafter, HLA-DR and CD25 expression were detected by flow cytometry. TNF- $\alpha$ and IFN- $\gamma$ content was determined by intracellular cytokine staining and flow cytometry (A). Released TNF- $\alpha$ and IFN- $\gamma$ were measured by ELISA (B). DMSO and FK866-treated cells were $84 \%$ and $83 \%$ viable, respectively. C, $5 \times 10^{6}$ PBLs were stimulated with PHA and PMA/ionomycin as above, or left unstimulated. Where indicated, $33 \mathrm{nM}$ FK866 with or without $10 \mu \mathrm{M}$ Na was added. Released IFN- $\gamma$ was measured by ELISA. Unstimulated PBLs treated with DMSO or FK866 were 96.3\% and 96.5\% viable, respectively. PBLs stimulated with PHA/PMA/ionomycin and treated with DMSO or FK866 were $89 \%$ and $89.5 \%$ viable, respectively. PBLs stimulated with PHA/PMA/ionomycin/Na and treated with DMSO or FK866 were $88 \%$ and $87 \%$ viable, respectively. D, PBLs were stimulated with PHA and PMA/ionomycin as describe for panel A. Where indicated $10 \mathrm{mM} \mathrm{Nam}$ or $50 \mu \mathrm{M}$ sirtinol were added. Thereafter, cells were harvested and intracellular IFN- $\gamma$ content was determined by flow cytometry. E, PBLs were stimulated with PHA and PMA/ionomycin as above in the presence or absence of $10 \mathrm{mM} \mathrm{Nam}, 50 \mu \mathrm{M}$ sirtinol, or $10 \mu \mathrm{M}$ PJ34. $42 \mathrm{~h}$ later, the supernatants were collected and IFN- $\gamma$ levels were detected by ELISA. Results are means $\pm S D$ of four experiments $(B, C, E)$. Panels $A$ and $D$ are representative of four separate experiments.

doi:10.1371/journal.pone.0007897.g006

Defective TNF- $\alpha$ synthesis as a consequence of $\mathrm{NAD}^{+}$shortage was attributed to reduced function of the $\mathrm{NAD}^{+}$-dependent sirtuin Sirt6 [29]. Interestingly, Sirt6-deficient animals develop profound lymphopenia as a result of a cell non-autonomous mechanism, suggesting a possible defect of relevant cytokines or growth factors involved in $\mathrm{T}$ cell function [31]. Thus, we evaluated whether IFN- $\gamma$ secretion inhibition may depend on reduced Sirt 6 activity. Indeed, two structurally unrelated sirtuin inhibitors, sirtinol and Nam, prevented IFN- $\gamma$ expression in $\mathrm{T}$ cells as shown by intracellular cytokine staining and IFN- $\gamma$ detection in the supernatants (Figure 6D, E) confirming a putative role for a sirtuin member in IFN- $\gamma$ synthesis. Conversely, the PARP inhibitor PJ34 did not affect IFN- $\gamma$ production (Figure 6E).
When evaluating Sirt6 levels in T lymphocytes, we found that Sirt6 transcription is induced by mitogenic stimulation (Figure 7A). To assess the role of Sirt 6 in IFN- $\gamma$ and TNF- $\alpha$ production by $\mathrm{T}$ cells we expressed a validated Sirt6 shRNA (S6 sh2) in Jurkat and $\mathrm{H} 9$ cells by retroviral transgenesis [32]. Indeed, S6 sh2 effectively downregulated Sirt6 mRNA and protein as shown in Jurkat cells (Figure 7B, G). No detrimental effect of Sirt6 silencing on cell viability was observed (data not shown). Jurkat cells with reduced Sirt6 levels showed reduced IFN- $\gamma$ and TNF- $\alpha$ production on stimulation with mitogens (Figure 7D, E). Conversely, IL-4 secretion was not affected by Sirt6 deficiency (Figure 7F). Sirt6 silencing led to reduced intracellular IFN- $\gamma$ levels in $\mathrm{H} 9$ cells stimulated with a mitogen cocktail (Figure 7G). Finally, splenocytes from Sirt6 knockout mice were found to secrete less IFN- $\gamma$ 

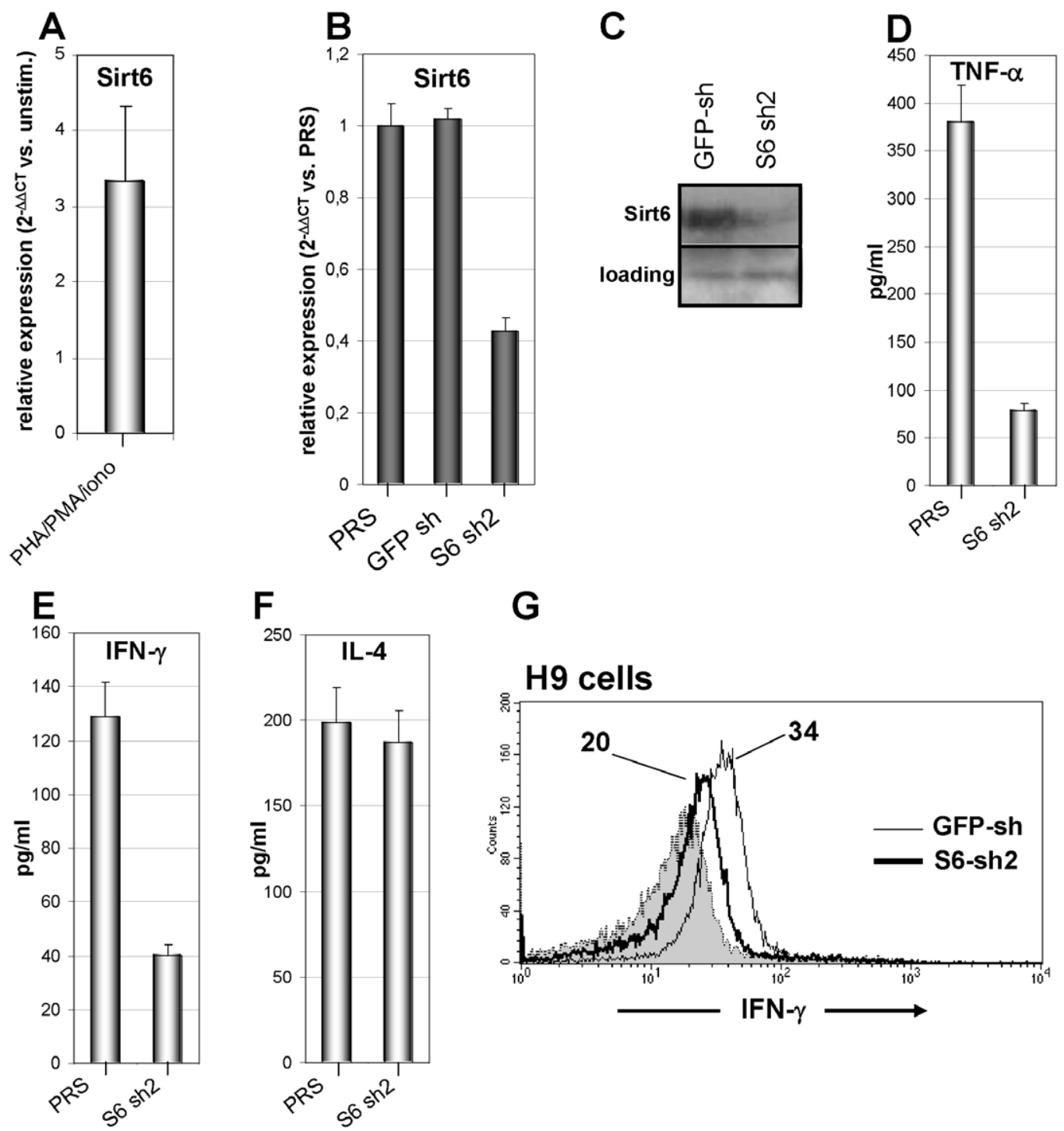

G

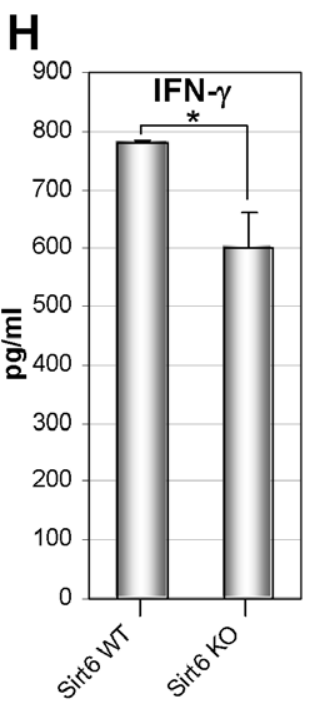

Figure 7. Evidence for an involvement of Sirt6 in IFN- $\gamma$ synthesis. A, PBLs were cultured for $24 \mathrm{~h}$ with or without PHA. Thereafter, Sirt6 levels were detected by Q-PCR. mRNA levels in PHA-stimulated cells were compared to those in unstimulated PBLs. B, C, Jurkat cells were transduced with PRS, (PRS) GFP-sh, or (PRS) S6 sh2, subsequently, Sirt6 mRNA levels or Sirt6 protein levels were determined by Q-PCR (B) and immunoblotting (C). D-F, Jurkat cells transduced with PRS or S6 sh2 were stimulated for $12 \mathrm{~h}$ with $5 \mu \mathrm{g} / \mathrm{ml} \mathrm{PHA}, 50 \mathrm{ng} / \mathrm{ml} \mathrm{PMA}$, and $0.5 \mu \mathrm{M}$ ionomycin. Thereafter, supernatants were harvested and TNF- $\alpha$ (D), IFN- $\gamma(E)$, and IL-4 (F) levels were determined by ELISA. G, H9 cells transduced with GFP-sh or S6 sh2 were stimulated for $12 \mathrm{~h}$ with $5 \mu \mathrm{g} / \mathrm{ml} \mathrm{PHA}, 50 \mathrm{ng} / \mathrm{ml} \mathrm{PMA}$, and $0.5 \mu \mathrm{M}$ ionomycin. Thereafter, intracellular IFN- $\gamma$ was detected by intracellular staining. Mean fluorescence intensity for IFN- $\gamma$ expression is indicated for each histogram. $\mathrm{H}, 3 \times 10^{6}$ splenocytes from wild type or Sirt6 KO mice/well were seeded in 24 well plates and stimulated for $24 \mathrm{~h}$ with $1 \mu \mathrm{g} / \mathrm{ml}$ Con A. Thereafter, supernatants were harvested and IFN- $\gamma$ levels were determined by ELISA. *: $p<0.05$. Results are means $\pm S D$ of three experiments $(A, B, D-F)$. Panel $C$ and $G$ are representative of three separate experiments. doi:10.1371/journal.pone.0007897.g007

than splenocytes from wild type animals (Figure $7 \mathrm{H}$ ). Thus, altogether these data are consistent with an involvement of Sirt6 in IFN- $\gamma$ synthesis.

\section{FK866 Reduces Demyelination and Disease Severity in EAE}

Given the capacity of FK866 to interfere with survival of activated $T$ cell and with the release of immunogenic cytokines, we sought to determine whether FK866 treatment might be advantageous in a prototypical autoimmune disease such as EAE, particularly after disease onset. FK866 was administered at $10 \mathrm{mg} / \mathrm{Kg}$ body weight twice daily starting 12 days post MOGimmunization of the mice, for a total of 10 days. Mononuclear cells from FK866-treated animals exhibited a significant decrease in the levels of intracellular pyridine dinucleotides (Figure 8A). As observed with human PBLs, $\mathrm{NAD}^{+}$and $\mathrm{NADH}$ were more severely reduced as compared to $\mathrm{NADP}^{+}$and NADPH. FK866 strikingly reduced the clinical disease score as described in Materials and Methods when compared with vehicle-alone treated controls, reaching statistical significance from day 19 onward (Figure 8B, and Table 1). The benefit of FK866 was fully retained until day 80 from immunization (not shown). The clinical effect of FK866 was associated with a marked reduction of demyelination in the spinal cord of treated mice (Figure 8C, and Table 1). FK866 showed no evident toxicity on renal and liver function, nor did FK866-treated mice show weight loss or increased frequency of 
A

B

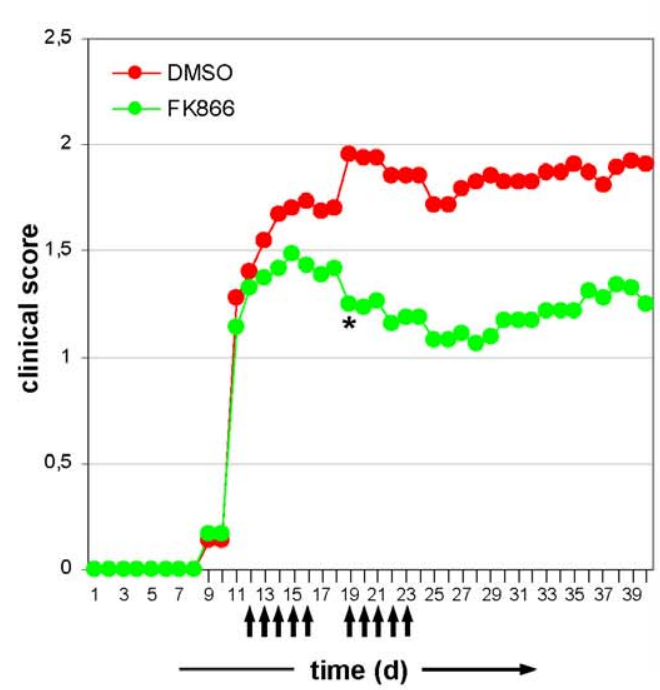

C

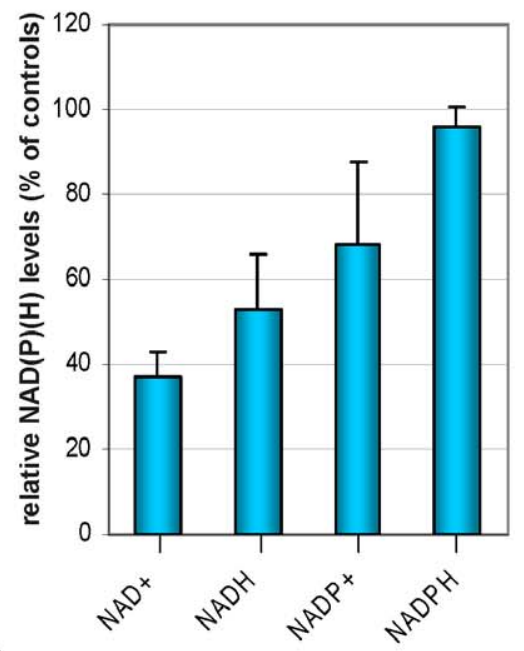

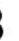

control
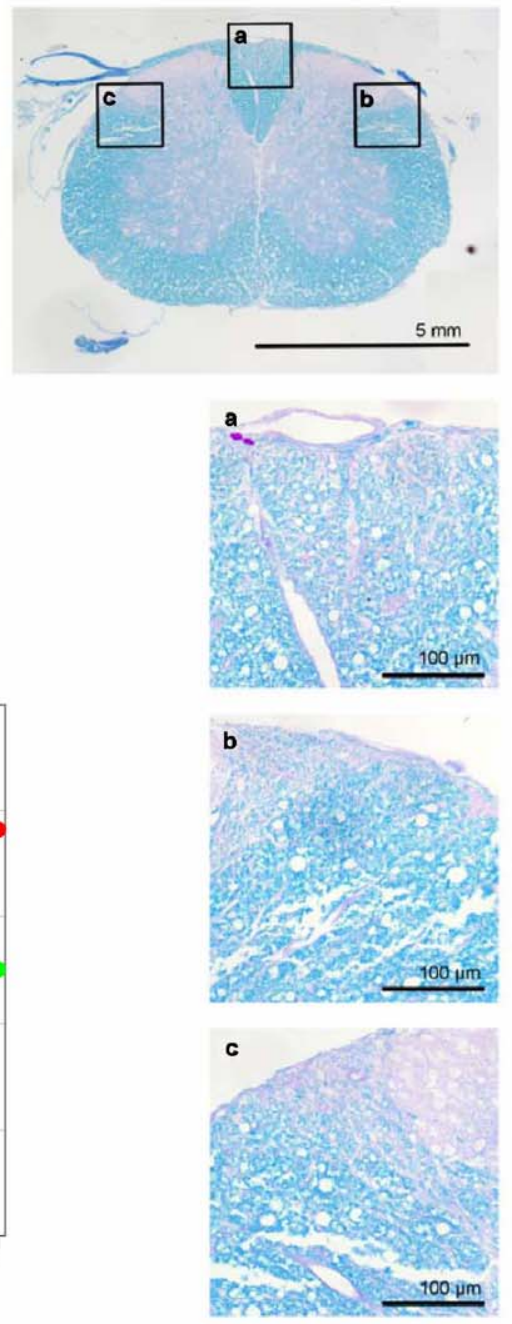

FK866
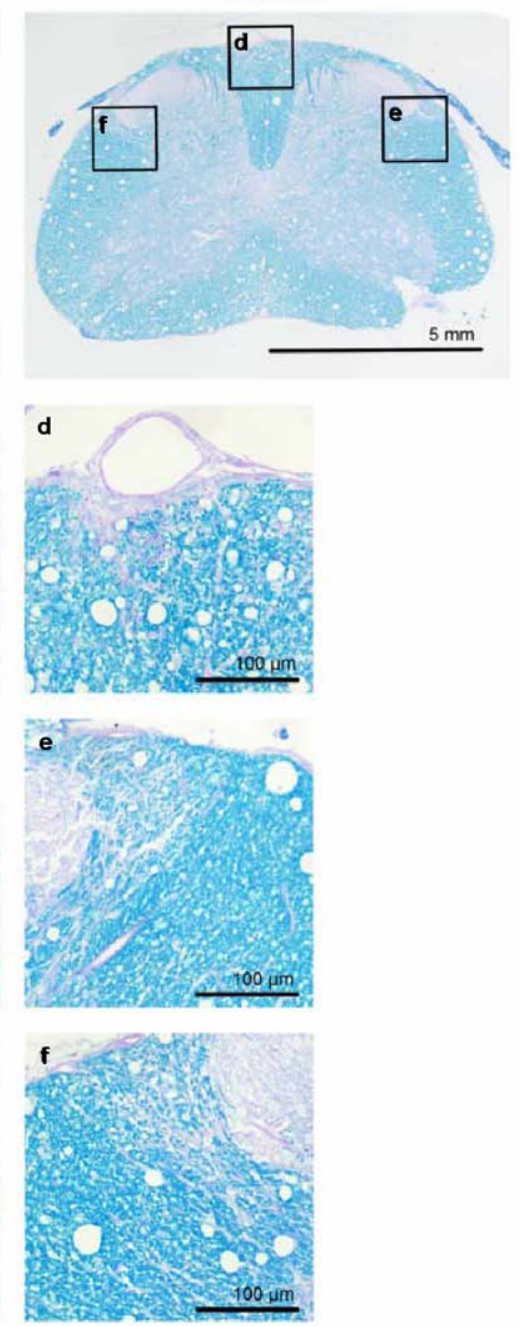

Figure 8. FK866 ameliorates EAE. $10 \mathrm{mg} / \mathrm{kg}$ body weight FK866 were administered to mice from day 12 after rMOG immunization for 10 days. A, $\mathrm{NAD}(\mathrm{H})$ and NADP $(\mathrm{H})$ levels were measured in mononuclear cells isolated from spleen and lymph nodes of treated or untreated animals at day 16. Dinucleotide levels in FK866-treated mice were expressed as \% of those detected in control animals. B, FK866 halts EAE severity compared with controls ( $p<0.05$ from day 19 onward). Arrows indicate the days of FK866 administration. C, Luxol fast Blue staining of the spinal cord shows areas of demyelination in control mice compared with FK866-treated animals. doi:10.1371/journal.pone.0007897.g008

concomitant infectious or neoplastic disease over a period of 80 days. Hence, FK866 is effective in treating EAE after disease onset in the absence of obvious toxicity.

\section{Discussion}

In this study, we show that activated $\mathrm{T}$ lymphocytes are crucially dependent on Nampt activity for their function and survival as they face massive $\mathrm{NAD}^{+}$depletion and cell demise when this enzyme is obstructed with FK866. Thus, increased susceptibility to $\mathrm{NAD}^{+}$lowering drugs emerges as a property of activated $\mathrm{T}$ lymphocytes that is susceptible of being targeted pharmacologically. The consequences of Nampt inhibition in unstimulated $\mathrm{T}$ lymphocytes appear to be less deleterious as these retain $\operatorname{NAD}(\mathrm{H})$ levels that are sufficient to ensure survival in the majority of the cells.

The high susceptibility of activated T cells to FK866 is due, at least in part, to PARP upregulation which per se leads to intracellular $\mathrm{NAD}^{+}$reduction, an occurrence normally prevented by Nampt $[8,10,12,16]$. The involvement of other enzymatic activities/metabolic processes in enhancing $\mathrm{T}$ cell susceptibility to FK866 is suggested by the fact that PARP inhibitors only partially protect activated T lymphocytes from FK866. Experiments aimed to assess the role of the ADP-ribosyl cyclase CD38 in conferring susceptibility to FK866 failed to detect major such effects of this enzyme. Conversely, a partial protection from FK866 was conferred to activated $\mathrm{T}$ cells by the sirtuin inhibitor sirtinol. Which one(s) of the sirtuin is (are) most active in $\mathrm{T}$ cells, and which role they play has to be defined yet. Nonetheless, our findings suggest that sirtuins may be responsible for consuming significant amounts of $\mathrm{NAD}^{+}$in $\mathrm{T}$ lymphocytes. In addition, sirtuin levels/ activity may increase in response to activation stimuli, as is the case of Sirt6, which we found to be upregulated in response to mitogens. Finally, since a 5-13-fold increase in $\mathrm{NAD}^{+}$kinase activity was detected in mitogen-stimulated T lymphocytes [10], another mechanism contributing to the exhaustion of the $\mathrm{NAD}(\mathrm{H})$ 
Table1. Clinical-pathologic features of EAE-affected mice treated with FK866.

\begin{tabular}{llllll}
\hline & & & & \\
\hline & $\begin{array}{l}\text { Disease incidence no./no. } \\
\text { total (\%) }\end{array}$ & $\begin{array}{l}\text { Disease onset, day after } \\
\text { immunization }\end{array}$ & $\begin{array}{l}\text { Mean maximum } \\
\text { neurologic score }\end{array}$ & Cumulative disease score & Demyelination score \\
\hline Control & $16 / 16(100 \%)$ & $10.5 \pm 0.9$ & $2.4 \pm 0.9$ & $53.9 \pm 23.6$ & $10.6 \pm 4.6$ \\
FK866 & $16 / 16(100 \%)$ & $10.3 \pm 0.9$ & $1.9 \pm 0.8$ & $37.7 \pm 22.4^{*}$ & $8.1 \pm 3.6^{*}$ \\
\hline$* \mathrm{p}<0.05$ (Mann-Whitney test). & & & &
\end{tabular}

doi:10.1371/journal.pone.0007897.t001

stores in activated $\mathrm{T}$ lymphocytes could be the shift of $\mathrm{NAD}^{+}$into the $\mathrm{NADP}(\mathrm{H})$ pool by the sequential action of $\mathrm{NAD}^{+}$kinase and glucose-6-phosphate dehydrogenase [33]. In line with this hypothesis is the finding that NADPH levels are virtually unaffected by FK866 in activated T cells while $\mathrm{NAD}^{+}$and NADH virtually disappear. Why other immune cell types are not affected by FK866 as much as activated $\mathrm{T}$ lymphocytes are remains a speculative matter. Its is conceivable that the enzymatic activities that actively consume $\mathrm{NAD}^{+}$and that we found upregulated in activated $\mathrm{T}$ cells may not be as much represented in other immune cells. Alternatively, other cells of the immune system may obtain their $\mathrm{NAD}^{+}$supplies (also) through metabolic pathways that are not affected by FK866. For instance, it is well documented that activated DCs upregulate indoleamine 2, 3-dioxygenase (IDO), a key enzyme in the $\mathrm{NAD}^{+}$synthesis pathway from tryptophan $[27,34]$.

T lymphocyte death due to $\mathrm{NAD}^{+}$exhaustion involves $\Delta \Psi_{\mathrm{m}}$ dissipation, ATP shortage, and autophagy. Previous studies suggested that FK866 induces apoptosis via cytochrome $c$ release and caspase-9 activation [3]. In FK866-treated T lymphocytes, we did detect released cytochrome $c$ in the cytosol (not shown). However, different caspase inhibitors failed to protect activated $\mathrm{T}$ lymphocytes from FK866 cytotoxicity. Thus, T cell death via FK866, although accompanied by cytochrome $c$ release, is caspase-independent and is therefore not a classical apoptotic process.

In addition to the Nam salvage pathway, $\mathrm{NAD}^{+}$synthesis from $\mathrm{Na}$ is apparently also an option for $\mathrm{T}$ lymphocytes. Previous studies found that Naprtl activity is present in human PBLs [14]. We confirmed Naprtl expression in human PBLs by Q-PGR and showed that this enzyme undergoes upregulation upon cell stimulation with mitogens. Consistently, we found that $\mathrm{Na}$ supplementation rescues $\mathrm{NAD}^{+}$levels when Nampt is inhibited allowing for T lymphocyte survival. The fact that FK866 induces lymphopenia in patients indicates that, under normal conditions, sufficient $\mathrm{Na}$ levels are not available to rescue $\mathrm{T}$ lymphocytes in vivo [5]. On the other hand, the consequences of Nampt inhibition could theoretically be rescued by increasing dietary $\mathrm{Na}$ intake or by pharmacological $\mathrm{Na}$ administration [27]. The expression in $\mathrm{T}$ lymphocytes of other enzymatic activities involved in $\mathrm{NAD}^{+}$ synthesis from NR and NaR remains unexplored and could provide insights into possible ways to modulate FK866 immunosuppressive activity and/or into mechanisms of resistance to this drug by cancer cells.

Not only $\mathrm{NAD}^{+}$shortage has deleterious repercussions on $\mathrm{T}$ cell viability. Before dying, $\mathrm{T}$ lymphocytes experience a phase of functional impairment where cytokine secretion is prohibited. In addition to reducing TNF- $\alpha$ production as described previously $[28,29]$, we found that FK866 also abolishes IFN- $\gamma$ expression. Importantly, in analogy to TNF- $\alpha$ [29], our data are consistent with an involvement of Sirt6 also in IFN- $\gamma$ synthesis, since RNAimediated Sirt6 removal reduces the expression of this cytokine. Moreover, splenocytes from Sirt6 KO mice were found to secrete less IFN- $\gamma$ than cells from wild type mice do. How Sirt6 is involved in $\mathrm{TNF}-\alpha$ and IFN- $\gamma$ production remains to be determined. Nonetheless, taken together, these observations depict the NamptSirt6 axis as an important regulatory pathway for cytokines involved in inflammation and cell-mediated immunity, that could be blocked with FK866 or, possibly, with Sirt6 inhibitors (Figure 9).

Based on these findings, we administered FK866 with the aim of curing EAE, a prototypical $\mathrm{T}$ cell-mediated autoimmune disease. Indeed, administration of FK866 after EAE onset successfully ameliorated the severity of disease. The clinical efficacy was demonstrated by a decreased cumulative disease score and by a consistent reduction in demyelination. Our data with FK866 in EAE are in line with recent reports of an anti-inflammatory activity of this drug in carrageenan-induced arthritis [28]. In fact, we cannot exclude that the benefit of FK866 on the clinical and histological manifestations of EAE may derive, at least in part, from effects that are unrelated to its activity on $\mathrm{T}$ cells. For instance, FK866 could (also) alleviate EAE by inhibiting TNF- $\alpha$ secretion by macrophages and microglia, thereby reducing inflammation and thus preventing neurological damage [28,29].

In conclusion, Nampt upregulation during T cell activation appears as an essential adaptation ensuring that sufficient $\mathrm{NAD}^{+}$ levels are available for metabolic reactions as well as for $\mathrm{NAD}^{+}$utilizing enzymes involved in DNA repair, signal transduction, and cytokine production. Targeting this metabolic pathway could represent a novel strategy to selectively eliminate activated $\mathrm{T}$ cells and block detrimental immune/inflammatory reactions such as those underlying autoimmune diseases, graft-versus-host disease, and transplant rejection.

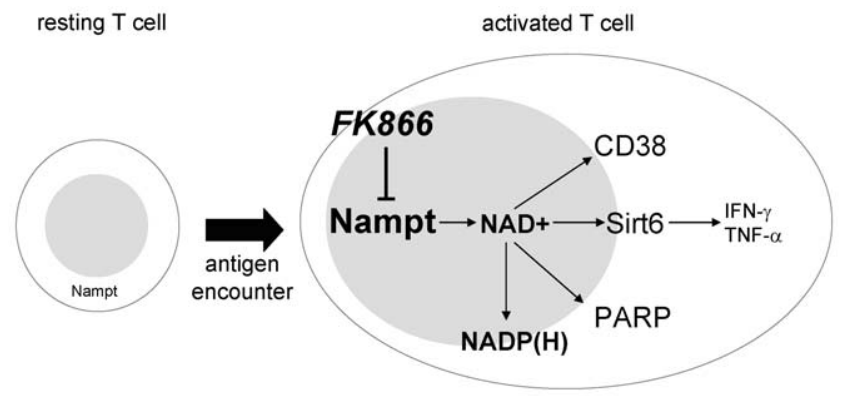

Figure 9. A putative model of Nampt's role in activated T lymphocytes. Nampt activity is responsible for providing sufficient $\mathrm{NAD}^{+}$supplies during T cell activation. $\mathrm{NAD}^{+}$, in turn, is required for ATP synthesis, metabolic reactions, and to replenish NADPH levels. In addition, $\mathrm{NAD}^{+}$represents the substrate of $\mathrm{NAD}^{+}$-degrading enzymes such as PARP, CD38, and the sirtuins. Among these, Sirt6 appears to have a central role in IFN- $\gamma$ and TNF- $\alpha$ production. Nampt inhibitors such as FK866 (and possibly Sirt6 inhibitors) could be used to modulate $\mathrm{T}$ cell-mediated immune responses and thereby be beneficial in immune disorders.

doi:10.1371/journal.pone.0007897.g009 


\section{Materials and Methods}

\section{Cell Lines and Reagents}

The T cell leukemia cell lines Jurkat, H9, PEER, and Phoenix were obtained from ATCG (LGC Standards s.r.l. Milan, Italy). Cells were grown in RPMI 1640-based medium supplemented with $10 \%$ FBS and antibiotics. The Bcl-2 overexpressing Jurkat cells and the respective vector control cells were a gift of Dr. Claus Belka (Department of Radiation Oncology, University of Tuebingen, Tuebingen, Germany) [22]. HeLa cells transfected with the sense $\left(\mathrm{CD}^{+} 8^{+}\right)$and antisense $\left(\mathrm{CD} 38^{-}\right)$cDNA for human fulllength CD38 were obtained and cultured as described [18]. Phytohematoagglutinin-P (PHA), concanavalin A (Con A), ionomycin, PMA, Nam, Na, Trp, 3-methyladenine (3-MA), sirtinol, LY294002, NU1025, 3-AB, PJ34, lipopolysaccharide (LPS), BAY 11-7082, PD098059, and tetramethyl rhodamine ethyl ester (TMRE) were all obtained from Sigma-Aldrich (Sigma Aldrich Italia, Milano, Italy). FK866 was generously provided by the NIMH Chemical Synthesis and Drug Supply Program.

\section{Peripheral Blood Lymphocyte (PBL), NK Cell, and Dendritic Cell (DC) Isolation}

Peripheral blood mononuclear cells (PBMCs) were isolated from blood samples obtained from healthy donors by Ficoll Hypaque density gradient centrifugation. $10^{7}$ mononuclear cells/well were plated in 6-well plates for $2 \mathrm{~h}$ in X-VIVO 20 medium (BioWhittaker, Lonza, Milan, Italy) to allow monocytes to adhere. Non-adhering mononuclear cells $(>80 \%$ CD3+ lymphocytes, PBLs) were harvested by washing with phosphate-buffered saline (PBS, Invitrogen Italia, Milan, Italy). For DC generation, adhering monocytes were cultured in RPMI 1640 medium supplemented with $10 \% \mathrm{FBS}$ and antibiotics in the presence of $100 \mathrm{ng} / \mathrm{ml} \mathrm{GM-}$ CSF and $20 \mathrm{ng} / \mathrm{ml} \mathrm{IL-4} \mathrm{(R \& D} \mathrm{Systems,} \mathrm{Wiesbaden,} \mathrm{Germany)}$ [35]. Where indicated, $100 \mathrm{ng} / \mathrm{ml}$ LPS were added to induce DC maturation. DC phenotype was confirmed by monitoring CDla, CD83, HLA-DR, CD80, CD86 and CD14 levels by flow cytometry. NK cells were isolated as described elsewhere [36].

\section{Immunostaining}

Cells were stained using FITC- or PE-conjugated mouse mAbs against CD3, CD25, HLA-DR (BD) and mouse IgG isotype control and analysed using a FACSCalibur (Becton Dickinson Italia, Milan, Italy). For intracellular TNF- $\alpha$ and IFN- $\gamma$ staining, cells were initially stained with a mouse monoclonal anti-CD3 (FITC- or PE-conjugated). Thereafter, cells were washed and incubated with $0.25 \%$ saponin and a FITC-conjugated antihuman IFN- $\gamma$ or a PE-conjugated anti-human TNF- $\alpha$ (both from Becton Dickinson). Finally, cells were washed and analysed by flow cytometry.

\section{Viability Assays}

$2.5 \times 10^{5} \mathrm{PBLs} /$ well were plated in 96 well plates in the presence or absence of the indicated stimuli. Viability was determined $120 \mathrm{~h}$ later by propidium iodide (PI) staining and flow cytometry (FACS Calibur, Becton Dickinson, BD Italia, Milan, Italy) within the lymphocyte gate. Viability was calculated with the following formula: 100-[(experimental death-spontaneous death $) /(100-$ spontaneous death)x100]. When DCs were used as a stimulator, $2.5 \times 10^{5} \mathrm{PBLs} /$ well were plated in 96 well plates with $2.5 \times 10^{4}$ irradiated $(3000 \mathrm{rad})$ allogeneic DCs. FK866 was added at the indicated concentrations 7 days later. For Annexin-V/PI staining, $3 \times 10^{6} \mathrm{PBLs} /$ well were plated in $1 \mathrm{ml}$ medium in 24-well plates in the presence or absence of $5 \mu \mathrm{g} / \mathrm{ml}$ PHA and treated with $33 \mathrm{nM}$ FK866 for the indicated amounts of time. Afterwards, cells were washed, stained with Annexin-V-FITC (Becton Dickinson) and PI and analyzed by flow cytometry.

\section{Light Microscopy}

Cells were imaged at room temperature using the $40 \times$ magnification of a Zeiss AXIOVERT200 microscope, camera Qlympus C-4040ZOOM. The image files were acquired with the software Olympus CAMEDIA Master 2.5, and subsequently processed using Microsoft Photo Editor.

\section{Proliferation Assay}

PBLs were seeded at $2 \times 10^{5}$ per well in 96-well plates. Proliferation was induced by adding PHA $(5 \mu \mathrm{g} / \mathrm{ml})$ and measured after $72 \mathrm{~h}$ by a $16-\mathrm{h}$ pulse with $\left[{ }^{3} \mathrm{H}\right]$ thymidine $(0.5 \mu \mathrm{Ci} /$ well; Amersham Life Science; Buckingham, U.K.).

\section{Mitochondrial Transmembrane Potential $\left(\Delta \Psi_{\mathrm{m}}\right)$ Determination}

$\Delta \Psi_{\mathrm{m}}$ was determined as previously described [37].

\section{ELISA for Detection of IFN- $\gamma$ and TNF- $\alpha$}

Supernatants harvested on day 2 from PBLs cultured in the presence of the indicated stimuli were analysed for the content of either IFN- $\gamma$ or TNF- $\alpha$ by ELISA kits from Peprotech Inc. (Princeton Business Park, Rocky Hill, NJ) according to manufacturer's instructions. IFN- $\gamma$ secretion by splenocytes isolated from wild type and $\operatorname{Sirt} 6 \mathrm{KO}$ mice (16-days old) [31] was detected using a sandwich ELISA kit purchased from R\&D Systems Inc. (Minneapolis, MN USA). Data are referred to a standard curve obtained with recombinant IFN- $\gamma$ or TNF- $\alpha$, respectively.

\section{Determination of the Intracellular $\mathrm{NAD}(\mathrm{H}), \mathrm{NADP}(\mathrm{H})$ and ATP Levels}

PBLs, resting or activated, were cultured in the presence or absence of FK866: cells were harvested and lysed with $0.6 \mathrm{M}$ perchloric acid (PCA) or $0.1 \mathrm{M} \mathrm{NaOH}$, to determine the content of $\mathrm{NAD}^{+}$or $\mathrm{NADH}$, and $\mathrm{NADP}^{+}$or $\mathrm{NADPH}$, respectively. The alkaline extracts were incubated at $70^{\circ} \mathrm{C}$ for $10 \mathrm{~min}$. Both acid and alkaline extracts were neutralized and the intracellular content of the various coenzymes was assessed with a sensitive enzyme cyclic assay, which exploits the use of alcohol dehydrogenase or of G6PD, to determine $\mathrm{NAD}(\mathrm{H})$ [38], or $\mathrm{NADP}(\mathrm{H})$ [39], respectively. To evaluate the content of ATP, cells were lysed in PCA and the neutralized extracts were analyzed by HPLC [40]. NAD $(\mathrm{H})$ and $\mathrm{NADP}(\mathrm{H})$ levels in murine mononuclear cells (MNCs) isolated from mice treated (or not) with FK866, were determined as in human PBLs. $\mathrm{NAD}(\mathrm{H}), \operatorname{NADP}(\mathrm{H})$, and $\mathrm{ATP}$ values were normalized to protein concentrations (micro-BCA kit, Pierce).

\section{siRNA Transfection}

Jurkat cells were transfected using the Nucleofector System (Amaxa GmbH, Cologne, Germany), without (control), or with StealthTM duplex short interference RNA (siRNA) targeting CD38. Cells were transfected in parallel with StealthTM Negative Control. After transfection, cells were incubated in the presence or absence of FK866 and intracellular NAD+ content was evaluated as described above. To confirm CD38 silencing, CD38 mRNA was detected by quantitative real-time PCR.

\section{Retroviral Transgenesis}

Empty pRETROSuper (PRS) and PRS GFP-sh were from Dr. Thijn Brummelkamp (Whitehead Institute for Biomedical Research, Cambridge, Ma, USA); PRS S6 sh2 was from Dr. Katrin 
F. Chua (Department of Medicine, Stanford University School of Medicine, Stanford, CA 94305, USA) [32]. Phoenix cells were plated in $4 \mathrm{ml}$ medium in $6 \mathrm{~cm}$-dishes and allowed to adhere for $24 \mathrm{~h}$. Thereafter, cells were transfected with $4 \mu \mathrm{g}$ plasmid DNA using Transit 293 (Mirus Bio, Madison, WI, USA) according to the manufacturer's instructions. The viral supernatant was harvested 36 and $48 \mathrm{~h}$ later and used to infect Jurkat and H9 cells in 24-well plates in the presence of $5 \mu \mathrm{g} / \mathrm{ml}$ protamine sulfate. Successfully infected cells were selected using $1 \mu \mathrm{g} / \mathrm{ml}$ puromycin.

\section{Q-PCR}

Total RNA was extracted from $5 \times 10^{5}$ cells using RNeasy kit reagents (Qiagen, Qiagen Italia, Milan, Italy). Total RNA (1 $\mu \mathrm{g})$ was reverse transcribed using random hexamers in a final volume of $50 \mu \mathrm{l} .5 \mu \mathrm{l}$ of the resulting cDNA was used for Q-PCR using a TaqMan 7900 HT Fast Real TimeAB [41]. Pre-designed primers and probes for Nampt, PARP1, CD38, Naprt1, and 18S were obtained from Applied Biosystems. Gene expression was normalized to housekeeping gene expression (18S). Comparisons in gene expression were done using the $2^{-\Delta \Delta \mathrm{Ct}}$ method [42].

\section{EAE Induction and Treatment Protocol with FK866}

This study was performed in compliance with the US Department of Health and Human Services Guide for the Care and Use of Laboratory Animals and approved by the Internal Review Board of the Advanced Biotechnology Center (ABC) in Genoa, Italy. Female C57BL/6J mice, 6 to 8 weeks old, were purchased from Harlan Italy (S. Pietro al Natisone, Italy). EAE was induced by MOG35-55 immunization according to a previously published protocol [43]. Mice received two intraperitoneal injections daily of $10 \mathrm{mg}$ FK866/ $\mathrm{kg}$ body weight or DMSO dissolved in $0.5 \mathrm{ml}$ PBS from day 12 through 16, and from day 19 through 23. Groups of 16 mice for each treatment (FK866 vs. DMSO) were used. Weight and clinical score were recorded daily. Clinical scores were assigned according to a standard and

\section{References}

1. Hasmann M, Schemainda I (2003) FK866, a highly specific noncompetitive inhibitor of nicotinamide phosphoribosyltransferase, represents a novel mechanism for induction of tumor cell apoptosis. Cancer Res 63: 7436-7442.

2. Khan JA, Tao X, Tong L (2006) Molecular basis for the inhibition of human NMPRTase, a novel target for anticancer agents. Nat Struct Mol Biol 13: 582-588.

3. Wosikowski K, Mattern K, Schemainda I, Hasmann M, Rattel B, et al. (2002) WK175, a novel antitumor agent, decreases the intracellular nicotinamide adenine dinucleotide concentration and induces the apoptotic cascade in human leukemia cells. Cancer Res 62: 1057-1062.

4. Nahimana A, Attinger A, Aubry D, Greaney P, Ireson C, et al. (2009) The NAD biosynthesis inhibitor APO866 has potent antitumor activity against hematologic malignancies. Blood 113: 3276-3286.

5. Holen K, Saltz LB, Hollywood E, Burk K, Hanauske AR (2008) The pharmacokinetics, toxicities, and biologic effects of FK866, a nicotinamide adenine dinucleotide biosynthesis inhibitor. Invest New Drugs 26: 45-51.

6. Pogrebniak A, Schemainda I, Azzam K, Pelka-Fleischer R, Nussler V, et al. (2006) Chemopotentiating effects of a novel NAD biosynthesis inhibitor, FK866, in combination with antineoplastic agents. Eur J Med Res 11: 313-321.

7. Yang H, Yang T, Baur JA, Perez E, Matsui T, et al. (2007) Nutrient-sensitive mitochondrial NAD+ levels dictate cell survival. Cell 130: 1095-1107.

8. Ying W, Sevigny MB, Chen Y, Swanson RA (2001) Poly(ADP-ribose) glycohydrolase mediates oxidative and excitotoxic neuronal death. Proc Natl Acad Sci U S A 98: 12227-12232.

9. Rongvaux A, Galli M, Denanglaire S, Van Gool F, Dreze PL, et al. (2008) Nicotinamide phosphoribosyl transferase/pre-B cell colony-enhancing factor/ visfatin is required for lymphocyte development and cellular resistance to genotoxic stress. J Immunol 181: 4685-4695.

10. Berger SJ, Manory I, Sudar DC, Berger NA (1987) Induction of the pyridine nucleotide synthesis pathway in mitogen-stimulated human T-lymphocytes. Exp Cell Res 169: 149-157.

11. Rongvaux A, Shea RJ, Mulks MH, Gigot D, Urbain J, et al. (2002) Pre-B-cell colony-enhancing factor, whose expression is up-regulated in activated lymphocytes, is a nicotinamide phosphoribosyltransferase, a cytosolic enzyme involved in NAD biosynthesis. Eur J Immunol 32: 3225-3234. validated 0 to 5 scale [43]. Unless moribund, mice were followed for at least 40 days following immunization. Disease incidence, onset, and maximum score were recorded for each mouse and expressed as mean $+/-\mathrm{SD}$. The cumulative disease score was calculated by summing the neurologic scores recorded daily for each mouse along the whole period of observation.

\section{Histology}

Euthanized mice were transcardially perfused with $4 \%$ paraformaldehyde before spinal cords were collected and embedded in paraffin. 5 - $\mu \mathrm{m}$ sections were stained with hematoxylin and eosin for detection of inflammatory infiltrates while Luxol fast Blue was used to observe myelin. All sections were analyzed with an Olimpus Provis AX70 (Olimpus Italia, Segrate, Milan, Italy) optical microscope. The areas of spinal cord demyelination were identified on individual images and traced manually on the composite images. Their surface was determined with Image ProPLUS 4 software (Media Cyberbetics, Silver Spring, MD) and expressed as a percentage of the total surface area. All histological evaluations were performed in a blind fashion.

\section{Acknowledgments}

The authors wish to thank Dr. Ilaria Rocco and Dr. Gabriella Cirmena for the excellent technical assistance; Dr. Claus Belka for providing the Bcl2overexpressing Jurkat cells; Dr. Filippo Ansaldi (Department of Health Sciences, University of Genoa) for the use of the BSL2+ facility; and the NIMH Chemical Synthesis and Drug Supply Program for generously providing FK866 for this study.

\section{Author Contributions}

Conceived and designed the experiments: SB FF AB BS FP RM AU AN. Performed the experiments: SB FF SmscM TF AP AG AD MS FB MC GZ EM DS AN. Analyzed the data: SB FF SmscM TF AP AG AD AU AN. Contributed reagents/materials/analysis tools: SB FF SmscM RM AU AN. Wrote the paper: SB FF AN.

12. Shaffer AL, Rosenwald A, Hurt EM, Giltnane JM, Lam LT, et al. (2001) Signatures of the immune response. Immunity 15: 375-385.

13. Feske S, Giltnane J, Dolmetsch R, Staudt LM, Rao A (2001) Gene regulation mediated by calcium signals in T lymphocytes. Nat Immunol 2: 316-324.

14. Sestini S, Jacomelli G, Pescaglini M, Micheli V, Pompucci G (2000) Enzyme activities leading to NAD synthesis in human lymphocytes. Arch Biochem Biophys 379: 277-282.

15. Cohen-Armon M (2007) PARP-1 activation in the ERK signaling pathway. Trends Pharmacol Sci 28: 556-560.

16. McNerney R, Tavasolli M, Shall S, Brazinski A, Johnstone A (1989) Changes in mRNA levels of poly(ADP-ribose) polymerase during activation of human lymphocytes. Biochim Biophys Acta 1009: 185-187.

17. Shubinsky G, Schlesinger M (1997) The CD38 lymphocyte differentiation marker: new insight into its ectoenzymatic activity and its role as a signal transducer. Immunity 7: 315-324.

18. Zocchi E, Daga A, Usai C, Franco L, Guida L, et al. (1998) Expression of CD38 increases intracellular calcium concentration and reduces doubling time in $\mathrm{HeLa}$ and 3T3 cells. J Biol Chem 273: 8017-8024.

19. Finkel T, Deng CX, Mostoslavsky R (2009) Recent progress in the biology and physiology of sirtuins. Nature 460: 587-891.

20. Rich PR (2003) The molecular machinery of Keilin's respiratory chain. Biochem Soc Trans 31: 1095-1105.

21. Shimizu S, Eguchi Y, Kamiike W, Funahashi Y, Mignon A, et al. (1998) Bcl-2 prevents apoptotic mitochondrial dysfunction by regulating proton flux. Proc Natl Acad Sci U S A 95: 1455-1459.

22. Belka C, Rudner J, Wesselborg S, Stepczynska A, Marini P, et al. (2000) Differential role of caspase-8 and BID activation during radiation- and CD95induced apoptosis. Oncogene 19: 1181-1190.

23. Lum JJ, DeBerardinis RJ, Thompson CB (2005) Autophagy in metazoans: cell survival in the land of plenty. Nat Rev Mol Cell Biol 6: 439-448.

24. Petiot A, Ogier-Denis E, Blommaart EF, Meijer AJ, Codogno P (2000) Distinct classes of phosphatidylinositol 3 '-kinases are involved in signaling pathways that control macroautophagy in HT-29 cells. J Biol Chem 275: 992-998. 
25. Billington RA, Genazzani AA, Travelli C, Condorelli F (2008) NAD depletion by FK866 induces autophagy. Autophagy 4: 385-387.

26. Danial NN, Korsmeyer SJ (2004) Cell death: critical control points. Cell 116 : 205-219.

27. Bogan KL, Brenner C (2008) Nicotinic acid, nicotinamide, and nicotinamide riboside: a molecular evaluation of NAD+ precursor vitamins in human nutrition. Annu Rev Nutr 28: 115-130.

28. Busso N, Karababa M, Nobile M, Rolaz A, Van Gool F, et al. (2008) Pharmacological inhibition of nicotinamide phosphoribosyltransferase/visfatin enzymatic activity identifies a new inflammatory pathway linked to NAD. PLoS ONE 3: e2267.

29. Van Gool F, Galli M, Gueydan G, Kruys V, Prevot PP, et al. (2009) Intracellular NAD levels regulate tumor necrosis factor protein synthesis in a sirtuindependent manner. Nat Med 15: 206-210.

30. Avalos JL, Bever KM, Wolberger C (2005) Mechanism of sirtuin inhibition by nicotinamide: altering the $\mathrm{NAD}(+)$ cosubstrate specificity of a Sir2 enzyme. Mol Cell 17: 855-868.

31. Mostoslavsky R, Chua KF, Lombard DB, Pang WW, Fischer MR, et al. (2006) Genomic instability and aging-like phenotype in the absence of mammalian SIRT6. Cell 124: 315-329.

32. Michishita E, McCord RA, Berber E, Kioi M, Padilla-Nash H, et al. (2008) SIRT6 is a histone H3 lysine 9 deacetylase that modulates telomeric chromatin. Nature 452: 492-496.

33. Pollak N, Niere M, Ziegler M (2007) NAD kinase levels control the NADPH concentration in human cells. J Biol Chem 282: 33562-33571.

34. Hwu P, Du MX, Lapointe R, Do M, Taylor MW, et al. (2000) Indoleamine 2,3dioxygenase production by human dendritic cells results in the inhibition of $\mathrm{T}$ cell proliferation. J Immunol 164: 3596-3599.
35. Nencioni A, Grunebach F, Zobywlaski A, Denzlinger C, Brugger W, et al. (2002) Dendritic cell immunogenicity is regulated by peroxisome proliferator-activated receptor gamma. J Immunol 169: 1228-1235.

36. Poggi A, Massaro AM, Negrini S, Contini P, Zocchi MR (2005) Tumor-induced apoptosis of human IL-2-activated NK cells: role of natural cytotoxicity receptors. J Immunol 174: 2653-2660.

37. Nencioni A, Lauber K, Grunebach F, Van Parijs L, Denzlinger C, et al. (2003) Cyclopentenone prostaglandins induce lymphocyte apoptosis by activating the mitochondrial apoptosis pathway independent of external death receptor signaling. J Immunol 171: 5148-5156.

38. Graeff R, Lee HC (2002) A novel cycling assay for cellular cADP-ribose with nanomolar sensitivity. Biochem J 361: 379-384.

39. Gasser A, Bruhn S, Guse AH (2006) Second messenger function of nicotinic acid adenine dinucleotide phosphate revealed by an improved enzymatic cycling assay. J Biol Chem 281: 16906-16913.

40. Guida L, Franco L, Zocchi E, De Flora A (1995) Structural role of disulfide bridges in the cyclic ADP-ribose related bifunctional ectoenzyme CD38. FEBS Lett 368: 481-484.

41. Miglino M, Grasso R, Varaldo R, Fugazza G, Colombo N, et al. (2006) Molecular analysis of the Imatinib-induced complete cytogenetic response in chronic myelogenous leukemia. Leuk Lymphoma 47: 1348-1351.

42. Pfaffl MW (2001) A new mathematical model for relative quantification in realtime RT-PCR. Nucleic Acids Res 29: e45.

43. Zappia E, Casazza S, Pedemonte E, Benvenuto F, Bonanni I, et al. (2005 Mesenchymal stem cells ameliorate experimental autoimmune encephalomyelitis inducing T-cell anergy. Blood 106: 1755-1761. 